\title{
Retirement investor risk tolerance in tranquil and crisis periods: experimental survey evidence*
}

March 2010

Associate Professor Hazel Bateman

Centre for Pensions and Superannuation, University of New South Wales

Sydney, NSW 2052, Australia.

Ph: + 61293853096

Email: h.bateman@unsw.edu.au

Associate Professor Towhidul Islam

Department of Marketing and Consumer Studies, University of Guelph

Guelph, Ontario NIG 2W1, Canada.

Ph: +1 (519) $8244120($ ext 53835)

Email: islam@uoguelph.ca

Professor Jordan Louviere

Centre for the Study of Choice, University of Technology Sydney

PO Box 123, Broadway NSW 2007, Australia.

Ph: +61 295143993

Email: jordan.louviere@uts.edu.au 


\author{
Professor Stephen Satchell \\ Trinity College, University of Cambridge \\ Trinity Street, Cambridge CB2 1TQ, United Kingdom.
}

Ph: +44 1223338409

Email: ses11@cam.ac.uk

\author{
Dr Susan Thorp [contact author] \\ School of Finance and Economics, University of Technology Sydney \\ PO Box 123, Broadway NSW 2007, Australia. \\ Ph: +6129514 7784 \\ Email: susan.thorp@uts.edu.au
}

\footnotetext{
*We thank Pure Profile for their generous assistance with the development and implementation of the internet surveys and Gordon Clark, participants at the 2009 Mid-West Finance Association Meetings, the Networks Financial Institute Workshop on Improving Financial Literacy and Reshaping Financial Behavior, the 2009 Econometric Society Australasian Meetings and the seminars at Macquarie University, University of Auckland and University of Tasmania for helpful comments. We acknowledge support from the Centre for the Study of Choice, University of Technology, Sydney, Bateman and Thorp acknowledge financial support under ARC DP0556775. Part of this work was completed while Thorp visited the School of Economics at the University of New South Wales and Trinity College, Cambridge.

Software used: Microsoft Word.
} 


\section{Introduction}

The impact of the global financial crisis of 2008 and 2009 on private pension assets has been severe. Asset prices crashed on a scale not seen since the Great Depression of the 1930s. The OECD estimates that global assets accumulated to finance retirement fell by $20-25 \%$ over 2008. Ireland felt the greatest impact, where pension assets fell by around 35\%, but the United States was close behind with an estimated decline of $25-30 \%$, followed by falls of around $20 \%$ in Canada and Australia (Antolin \& Stewart 2009). Individual pension accumulations felt the brunt of the impact: in the United States, the average defined contribution plan balance fell by $16 \%$, from $\$ 31,800$ in 2007 to $\$ 26,578$ by mid 2009 (Copeland 2009).

This period of widespread losses and uncertainty coincides with worldwide moves towards individual pension accounts. The new pension systems transfer the risk and responsibility of retirement saving and investment decisions from plan sponsors to individuals. And the new choice burden is heavy: Australian employees, for example, must (subject to the availability of default options) decide on investment of their mandatory retirement savings contributions, choosing from up to 2000 managed funds (APRA 2009). Swedish retirement savers must choose from over 750 mutual funds, and US 401(k) plan participants also have to make allocations to asset classes and managers. These pension systems will work efficiently only if individuals are able to make investment allocations in their own best interest.

Investment risk is a key element of these decisions. Retirement welfare depends on how risk is explained by pension providers, how it is understood, and how it is managed in portfolios, but economic and financial turmoil may impinge on any of these important processes. 
Standard finance theory views the investment decision as a straight forward trade-off between risk and return, where the 'rate of exchange' depends on (usually constant) aversion to risk. The economic agent is assumed to correctly understand stochastic assets returns and the benefits of diversification, and is able to calculate an allocation that maximizes utility. In a choice experiment conducted during the relative economic calm of March 2007 (Bateman, Louviere, Thorp, Islam \& Satchell 2009), we tested the extent to which retirement savers followed these predictions. Results differed significantly among investors of different ages and income levels: younger investors were more often conventionally risk averse whereas some groups of older, higher income individuals reacted positively to both higher returns and increasing risk. We presented risk as a widening range of possible investment outcomes, a highly rated way of conveying risk information (Vlaev, Chater \& Stewart 2009).

Here, we aim to evaluate the impact of severe market shocks on investor risk tolerance and investment choice by repeating the choice experiment during the turbulent and gloomy conditions experienced in October 2008, immediately following the collapse of Lehman Brothers and sharp declines in world equity values. ${ }^{1}$ We are interested in whether changes to the external environmental between the 2007 and 2008 surveys cause people to revise overoptimistic decisions or to exhibit myopic loss aversion in crisis-period choices, even though the information set within the experiment stays constant.

Specifically, we use survey responses to estimate preferences for risk and return among (latent) groups of respondents and also to directly infer the cross-section of risk aversion for each survey sample so that, by comparing results for 2007 and 2008, we can detect changes in preferences caused by the external crisis. 
From the perspective of conventional theory, we might expect different investment choices in tranquility and crisis if risk aversion is non-constant and/or if large asset-price shocks lead individuals to change their subjective views on asset returns. Further, some risk preference measures vary with levels of wealth. On the other hand, behavioral researchers have noted the propensity for investors to exhibit overconfidence and over optimism in bull markets (Kahneman \& Riepe 1998) and to exhibit myopic loss aversion (Benartzi \& Thaler 1995), behaviors which can also explain swings in portfolio choice during and after crises.

Numerous studies have been conducted to understand and elicit risk aversion. These fall into several categories: laboratory studies of lottery-choice decisions using, for example, the experimental design of Holt and Laury (2002), analysis of survey data on real financial behavior to estimate risk aversion empirically (see, for example Ameriks \& Zeldes 2004; Gerrans \& Clark-Murphy 2004), experimental surveys of hypothetical investment choice decisions (see Bateman et al. 2009), as well as the analysis of responses to risk profiling questionnaires (Hallahan, Faff \& McKenzie 2003). Age and income dominate as key determinants of risk tolerance (Bateman et al. 2009; Clark \& Strauss 2008), although some studies also find significant effects from gender and wealth (Speelman, Clark-Murphy \& Gerrans 2007, Hallahan et al. 2003). Our study contributes to this literature by assessing, in a controlled way, the impact of external events

Plan providers, public regulators and researchers are particularly concerned about how investment choice menus are constructed and composed and what factors may influence individuals' decisions (Agnew \& Szykman 2005; Benartzi \& Thaler 2007). Findings indicate characteristics of menus and personal and demographic characteristics are often important, while behavioral research contends that individuals faced with complex decisions may 
demonstrate over-confidence or other biases, or rely on rules of thumb (Tversky \& Kahneman 1974; Benartzi, Peleg \& Thaler 2009). We contribute to this expanding debate on retirement savings choice design by evaluating the impact of demographics and design features on stated preferences.

In the next section we outline the experimental design, describe the samples and introduce relevant theory.

\section{Method}

Except for the economy-wide economic and financial conditions and the sample of respondents, the web-based experimental surveys we conducted in 2007 and 2008 were identical in design and presentation of investment choices.

\section{Sample, Presentation and Design}

The online web panel provider, PureProfile recruited two samples of individuals aged 1865 on our behalf: 819 people in March 2007 and 919 in October 2008. Each sample was constructed to match demographic patterns of the Australian population (aged 18-65) which explains the slightly different sample sizes. PureProfile invited selected members of their 300,000 household panel to join the survey by email or via their website, informed respondents that this was a university project, and paid those who completed the survey a nominal sum of $\$ 4.20$.

Individual retirement savings coverage is mandatory for all Australian employees aged 18-65 who earn at least $9 \%$ of average earnings, so almost all adults are familiar with the broad structure of the pension arrangements. Before making their investment choices, respondents read 
a brief explanation (Appendix 1) of the investments offered. Participants also answered questions about personal circumstances and demographics, and completed a risk profiling questionnaire designed as a financial planning tool by a major pension provider. Scores from the profiling questionnaire can be used to group respondents in a risk-tolerance range from 'conservative' to 'aggressive'. 2

\section{Sample demographics and risk profiling}

Demographics: By design, the demographic features of our samples are largely unchanged between the two surveys (Table 1). The genders are evenly represented and most respondents are partnered, have tertiary education, are full-time workers or students, own a car and a house, and hold investments or savings outside the pension system. Both samples include a good cross-section of ages. Large minorities are single, have secondary education only and do not own a home. In both samples almost a third classified their employment as professional or management, with the smallest occupational representations being tradespersons, laborers and transport workers. Around $60 \%$ of the sample reported income slightly below the Australian Bureau of Statistics measure of $60^{\text {th }}$ percentile household income in 2007-08 and close to $90 \%$ below the $90^{\text {th }}$ percentile.. ${ }^{3}$

[Insert Table 1 here]

Risk profiling: Despite the sharp deterioration in economic conditions at the time of the 2008 survey, the scores from the risk profiling questionnaire were almost identical in both sets of responses: around $76 \%$ of respondents scored in the middle range as 'balanced' with virtually no-one classified as 'aggressive' and very few 'conservatives'. In fact the only demographic indicator of a change of attitudes between the 2007 and 2008 surveys can be seen in responses to 
the question, 'Do you own stocks and shares?'. The percentage of the sample who answered 'no, but considering' fell from 41 to 31 and the number responding 'no, not interested' rose from 16 to 28 between 2007 and 2008. This suggests an intention to be wary of the stock market in the future among non-stock owners but not of ex post portfolio rebalancing by those already invested, since the number of respondents who owned stocks did not change significantly between the two samples.

\section{Design}

Subjects then chose from 16 tables of six investment options, indicating their 'most likely' and 'least likely' choices of investment option for a(hypothetical) $\$ 1,000$ pension ('superannuation') contribution. ${ }^{4}$ Five of the options differed by the proportion of equities and cash (ranging from 100 percent cash/0 percent equities to 75/25, 50/50, 25/75 and 0/100) while the sixth was a retirement savings account (RSA), which is similar to a bank account. ${ }^{5}$

Attributes: The theoretically important characteristics of investment options are risk and return. We varied (gross) return, fees and risk for each option using a fractional factorial design for the choice sets, based on the $\mathrm{L}^{\wedge \mathrm{MA}}$ in Louviere, Hensher and Swait (2000). We fixed gross returns in every choice set at the median 10 year accumulation in (real) dollars for each option, but the investment management fees (\% p.a.) and risk varied over four option-specific levels. (Table 2)

[Insert Table 2 here]

Fees were an annual percentage of account balance. The complex fees charged on actual retirement savings accounts we summarize using a single 'Investment management fee' calibrated to the range of fees charged by retail providers of managed funds, with four levels for 
each of the six investment options. ${ }^{6}$ This structure captures the higher fees charged by active equity managers. Changes to investment management fees interact with constant differences in the gross return for each portfolio to create variation in net returns.

We described risk to respondents as a range bounded by the 'likely worst case accumulation after 10 years' and 'likely best case accumulation after 10 years'. The four levels were quantile ranges from 10 year account values of the $\$ 1,000$ investment: the extreme minimum and maximum of the empirical distribution, 5-95th, 10-90th and 20-80th quantile ranges. We used bootstrapped historical returns to construct the empirical distribution from which the quantiles could be drawn, by taking sufficient random draws from a monthly series for real returns to compound into a 10 year gross return, and repeating that procedure 5,000 times. The historical monthly returns series used for the bootstrap runs from July 1986 to March 2006 and includes the 1987 stock market crash during which the equity price index fell around 40\%, an event comparable in scale to the losses experienced in late $2008 .{ }^{7}$ For estimation purposes, we inferred (annualized) portfolio variance for each range used in the choice sets by computing the volatility of the appropriate truncation of the bootstrapped returns distribution.

There is no universally accepted method for presenting investment risk to retirement savers in pension fund prospectuses, and the ranges we use here are certainly not typical. Some pension funds simply label investments as 'low', 'medium' or 'high risk' while others suggest the risk attitude of the investor, such as 'conservative' or 'aggressive'. Another common approach is to report the likely frequency of negative annual returns from some investment product over a fixed number of years. While most conventional measures focus only on the probability of losses, the range measure we use in these experiments shows extreme upside as 
well as downside outcomes and incorporates empirically observed skewness. We go this way because expected utility theory treats both unexpected gains and losses as risk. Our choice of risk framing is supported by Vlaev et al. (2009) who find that that range presentation received the highest ranking and resulted in more stable risk preferences.

Table 3 shows an example of a choice set.

[Insert Table 3 here]

\section{Theoretical Background}

The structure of our choice sets derives from basic finance theory where the investment decision as a straightforward trade-off between risk and return.

Investment choices. In this context, consider a mean variance $(M V)$ investor $(i)$ with expected utility, $V_{i}$, where

$$
V_{i}=\mu_{i}-\eta_{i} \sigma_{i}^{2}
$$

Here, $\mu_{i}$ is the expected rate of return of investor $i$ 's investment portfolio, $\sigma_{i}^{2}$ is his/her portfolio variance and $\eta_{i}$ is his/her risk parameter. Equation (1) is a certainty equivalent form for expected utility over wealth where $\eta_{i} \sigma_{i}^{2}$ is the risk premium and $2 \eta_{i}$ is absolute risk aversion.

Utility for each portfolio $V_{j}$, is a function of the portfolio option $j$ return and variance which change first with the proportional exposure to stocks in each option, and then over four option-specific levels, as set out in Table 2. (For the time being we set aside the index $i$ for an individual investor.) 


$$
V_{j}=V_{j}\left(\theta_{j}\right)=\mu_{s} \theta_{j}+\mu_{c}\left(1-\theta_{j}\right)-\phi_{j}-\eta\left[{\theta_{j}}^{2} \sigma_{s}^{2}+2 \theta_{j}\left(1-\theta_{j}\right) \sigma_{s c}+\left(1-\theta_{j}\right)^{2} \sigma_{c}^{2}\right]
$$

where $\theta_{j}$ is the proportion of the portfolio allocated to stocks, $\mu_{s}$ is the return to stocks, $\mu_{c}$ is the return to cash, $\phi_{j}$ is the fee deducted from returns, $\sigma_{s}{ }^{2}$ is the variance of stock returns, $\sigma_{s c}$ is the covariance between stocks and cash and $\sigma_{c}{ }^{2}$ is the variance of cash returns. ${ }^{8}$

The investor chooses between the six options by comparing the expected utility of each and selecting the one with the highest utility and we can infer that $V_{k} \succ V_{j}$ when the difference $V_{k}-V_{j}$ is positive.

We can also compare each of the stock/cash portfolios with the constant choice. In our experiment this is the retirement savings account which is fixed and offered in every choice set. The difference in utility between options $j=1, \ldots, 5$ and the retirement savings account (portfolio option $r)^{9}$ simplifies to

$$
\left(V_{j}-V_{r}\right)=\left\{\left[\mu_{s} \theta_{j}+\mu_{c}\left(1-\theta_{j}\right)-\mu_{r}\right]-\phi_{j}\right\}-\eta\left[\theta_{j}{ }^{2} \sigma_{s}{ }^{2}+2 \theta_{j}\left(1-\theta_{j}\right) \sigma_{s c}+\left(1-\theta_{j}\right)^{2} \sigma_{c}{ }^{2}\right]
$$

where $V_{r}$ is the utility of the retirement savings account, and $\mu_{r}$ is the return to the retirement savings account. (There is no fee and no variability of return on the retirement savings account.) So we have two explanatory variables: net return, given by the term in the curly brackets in equation (3), which is excess return over the risk free rate, net of fees; and portfolio variance, given by the term in the square brackets. Individual variations in preferences appear in the risk parameter, $\eta_{i}$. 
Using these data we estimate a discrete mixture model of preferences over risk and return conditioning on relevant demographics and compare with the predictions of mean-variance theory.

Risk aversion. We can also use responses of individuals to map out the cross-section of risk aversion in our sample of investors. Conditioning on attribute levels and the proportions of shares and cash for each option $j$, we can infer a range of values for $\eta$ for which it will be optimal for a respondent with risk aversion in that range to choose option $j$ in each choice set. In other words, we can compute the range of values of $\eta_{i}$ over which one option will be most preferred $\left(\max \left\{V_{i j}\right\}_{j=1}^{6}=V_{j}\right)$, and the range for which it would be least preferred $\left(\min \left\{V_{i j}\right\}_{j=1}^{6}=V_{j}\right)$. If, for all comparisons between investment options by an individual in any given choice set one investment option dominates, $V_{k}>V_{j}, \forall k$, then the following inequality must hold, defining a maximum for risk aversion consistent with that 'best' choice:

$$
\eta<\frac{\mu_{s}\left(\theta_{k}-\theta_{j}\right)+\mu_{c}\left(\theta_{j}-\theta_{k}\right)+\phi_{j}-\phi_{k}}{\left[\sigma_{s}^{2}\left(\theta_{k}^{2}-\theta_{j}^{2}\right)+2 \sigma_{s c}\left(\theta_{k}\left(1-\theta_{k}\right)-\theta_{j}\left(1-\theta_{j}\right)\right)+\sigma_{c}^{2}\left(\left(1-\theta_{k}\right)^{2}-\left(1-\theta_{j}\right)^{2}\right)\right]}
$$

As noted earlier, our repeated experiments follow a fractional factorial design based on the $\mathrm{L}^{\wedge \mathrm{MA}}$ approach in Louviere, Hensher and Swait (2000) which generates 64 distinct choice sets, 16 of which are presented to each respondent. Each choice set is offered around 200 times over the entire survey. As the proportions in stocks, $\theta_{j}$ and $\theta_{k}$, in each pair of options vary between zero and one, and as the option-specific attributes of net return and variance change between the four levels, we can use (4) to derive a series of inequalities that define ranges for $\eta$ 
for which each option $k$ is preferred to all others in a choice set. Each of the 64 choice sets thus embeds an associated pattern of risk tolerance.

By collecting the 16 best and worst choices of each respondent and mapping them into the risk pattern of the relevant choice sets, we can back out ranges for each respondent's risk aversion parameter $\eta_{i}$. These 16 individual ranges may or may not uniquely define an intersection: some respondent's choices produce non-intersecting ranges of risk tolerance and no well-defined range for $\eta_{i}$ emerges. Choices may be consistent with risk neutral and risk loving behavior, as well as with risk aversion. We can use these inferred risk aversion levels to compare responses between 2007 and 2008 .

Using our estimated model and direct inference we can compare investment choices and risk aversion between the relatively tranquil period of early 2007 and the crisis period of late 2008.

\section{Results}

\section{Observed Choices}

Table 4 shows the 13,104 best and worst choices for the March 2007 sample and the 14,699 choices from the October 2008 sample. ${ }^{10}$

[Insert Table 4 here]

In the 2007 survey, the higher the proportion of shares in an option, the more often it option was chosen as 'most likely'. More than $60 \%$ of best choices were allocated to the options with $75 \%$ or more in shares whereas the savings account and $100 \%$ cash options collectively 
accounted for only 7\%. Likewise, the savings account was the most common 'worst' choice (59\% of least preferred choices), the $100 \%$ cash and share portfolios were least preferred in $12-$ $15 \%$ of observations, while the diversified portfolios were the least common 'worst' choices.

The 2008 survey was conducted between 17-24 October, soon after the failure of Lehman Brothers and following a well-publicized 30\% decline in Australia's benchmark share price index (ASX200) over the previous two months. The Australian dollar had also depreciated very rapidly (around 30\% against the USD over the course of a few weeks) and news media were dominated by reports of financial and economic crisis. In the gloomy environment, and after substantial reductions in the wealth of equity investors, preferences of respondents for high-risk allocations appeared to moderate. The $100 \%$ shares choices dropped by seven percentage points to around $26 \%$ of the sample, in favor of higher cash weightings, particularly the 50:50 allocation, which increased by four percentage points to $23 \%$ of best selections. A 50:50 allocation is sometimes chosen to minimize regret (Michenaud \& Solnik 2005; Bell 1982; Loomes \& Sugden 1982) but may also be an approximation to a ' $1 /$ n' rule (Benartzi \& Thaler 2001, Huberman \& Jiang 2006). The 100\% shares option also attracted six percentage points more worst choices in 2008, rising from $12 \%$ to $18 \%$, and the RSA and $100 \%$ cash options were chosen as worst less frequently. Nonetheless, the investments with more than $75 \%$ in shares were still the most popular choices.

At first glance, the raw data suggest two aspects of risk preferences worth investigating: first, respondents seem to show a strong preference for riskier investments, and second, risk preferences seem weaker at the time of the 2008-09 financial crisis. We address these questions by extracting information on risk preferences directly from individual choices, and then using 
econometric modeling to estimate latent preferences classes, and testing the restriction that the parameters of the model are constant for 2007 and 2008.

\section{Inferred Risk Preference Patterns}

We present some observations on the risk preference patterns evident in the survey data beginning with an example. Take an individual at random from the 2008 survey. This particular respondent was presented with 16 choice sets, numbered 17-32 (out of a total of 64), each with a unique pattern of portfolio attributes that define two sets of risk parameter ranges $\left\{\eta_{j}^{+} \eta_{j}^{-}\right\}_{j=1}^{6}$, one defining ranges where each investment option will be best $\left(\max \left\{V_{i j}\right\}_{j=1}^{6}=V_{j}\right)$ and the second defining ranges for which each option will be worst $\left(\min \left\{V_{i j}\right\}_{j=1}^{6}=V_{j}\right)$.

Two features of the experimental design are worth keeping in mind during this discussion: first, one or two of the six investment options in each choice set may be dominated by neighboring investment options at any risk aversion; and second, the risk range is not always increasing as the proportion of shares rises. We also impose an artificial boundary on the range of risk parameters. We choose an upper bound for risk aversion by calculating the value of the parameter at which it is optimal to choose the retirement savings account in every choice set, $\eta=373$. There is no similar lower bound for $\eta$ at which it was optimal to choose the $100 \%$ shares option in every set. In other words, the 25:75 cash/shares portfolio (investment option 4) was always better than $100 \%$ shares (investment option 5) for risk-loving respondents in a proportion of the 64 choice sets, no matter how risk tolerant they were. For the affected choice sets, this dominance was evident from $\eta=-15$ so our measure of risk preference runs from $15 \leq \eta \leq 373$ which corresponds to a range for absolute risk aversion range of $-30 \leq 2 \eta \leq 746$. 
Most-preferred choices and risk preferences. Table 5 shows the values of $2 \eta$ for which it is optimal to choose each option as 'most preferred' or 'best' in each of the 16 choice sets and the implied risk parameter associated with the choices of the example respondent. The respondent's best choices create an intersection over a narrow interval consistent with a risk parameter of $-8 \leq 2 \eta \leq-7$. We identify this interval by taking the lowest maximum inf $\left\{\eta_{i j, k}^{+}\right\}_{k=1}^{16}$ and highest minimum $\sup \left\{\eta_{i j, k}^{-}\right\}_{k=1}^{16}$ for all $k=1, \ldots 16$ pairs $\left(\eta_{i j}^{+} \eta_{i j}^{-}\right)$implied by the respondent's choices and we call this their risk preference range. These choices define an interval $\left(\eta_{i j}^{+} \eta_{i j}^{-}\right)^{*}$ that is inside the ranges $\left(\eta_{i j}^{+} \eta_{i j}^{-}\right)$for all 16 choices.

[Insert Table 5 here]

Not everyone is so consistent. For the majority of respondents, we cannot define an intersection interval because their implied risk parameter ranges form discontinuous intervals. In fact, we can identify a well-defined risk parameter interval for only $14.8 \%$ of the sample (122/819 respondents) in 2007 and $11.8 \%$ of the sample (108/919 respondents) in 2008, using 'most likely' choices.

Remarkably, those who do choose consistently include a large number who show tendencies to risk loving choices. The median value of the midpoints of risk parameter intervals was negative in both years: -1 in 2007 and -0.5 in 2008. The first quartile is around -7(-7) and the third quartile begins around 2(67.5) for 2007(2008). The graph in Table 6, which presents distributions of midpoints of the risk parameter intervals for both 2007 and 2008, suggests that the cross-section of risk preferences is very wide. 
For both samples, the correlations between inferred risk preference and age, gender, education and household income were insignificantly different from zero, but the correlation with the scores from the risk profiling questionnaire were significant and negative, indicating that the two methods of gauging risk tolerance may be inconsistent for some respondents.

While many respondents in both samples appear to be strongly risk loving and may make choices that go against their risk profile, we do observe an increase in mean risk aversion in 2008 over 2007 (marginally significant). This indicates a more general observable shift towards risk aversion across the distribution during the financial crisis (see Table 6).

[Insert Table 6 here]

Least-preferred choices and risk preferences: For 'least preferred' or 'worst' choices there is much less natural variability in the choice sets and consequently less power to distinguish different tastes for risk (see Table 7). In this example of 16 choice sets, the retirement savings account (investment option 6) minimizes utility for the range of parameters we might think of as conventionally moderate risk aversion and is also worst for any respondent with risk neutral or risk loving preferences. At higher levels of risk aversion, the $100 \%$ shares portfolio (investment option 5) is most often worst. The choices we observe in Table 4 match up to this pattern in the design, with investment options 5 and 6 (25:75 cash/shares and 100\% shares) collecting $17 \%$ (24\%) of worst choices in 2007(08). Our example respondent chooses his/her least preferred option consistently with the risk parameter we inferred from his/her best choices, always selecting option 6 (the retirement savings account), and thus defining a range of risk aversion for worst choices $-30 \leq 2 \eta \leq 4$, which includes the best choices range $-8 \leq 2 \eta \leq-7$.

[Insert Table 7 here] 
A much larger proportion of the samples have 'worst' choice parameter ranges that are consistent (66\% of both the 2007 and 2008 samples), but many of these fall into two distinct intervals as can be seen in the distributional graph in Table 8. The midpoint data are bimodal, grouped into those who choose the least, and those who choose the most, risky investments as worst, but this is almost surely an effect of the choice set design, as explained above. We can say little about the cross-section of risk preferences from these observations. However we do observe again a slight increase in risk aversion between the two surveys. In addition, correlation analysis shows that risk aversion is significantly decreasing in the education level of the respondents, and again significantly negatively related to the score from the risk profiling questionnaire, in both 2007 and 2008. Risk aversion is significantly lower for males than for females in the 2008 survey and significantly lower for people with higher income households in 2007.

[Insert Table 8 here]

\section{Estimated Latent Class Preference Model}

In addition to direct inference, we estimate the preferences (investment choices) of survey respondents using a latent class model where discrete but unobserved classes of participants have different preferences. Conventional latent class models allow preference parameters to vary between groups of investors but restrict the scale parameter of the random utility error to be fixed at one for all classes, possibly confounding preference variability and differences in underlying variability (Louviere \& Eagle 2006; Fiebig, Keane, Louviere \& Wasi 2009). Here we relax the restriction that the scale parameter is fixed across the whole population (Magidson and Vermunt 2005) and estimate the latent classes for both preferences (investment choices) and scale (choice 
variability). Class memberships are allowed to be functions of demographic covariates. A detailed description of the modeling approach is set out in Appendix 2.

It turns out that preference classes in our estimated models identify some interesting distinctions based on age and income, and that general variation in response (scale class) may be linked to underlying risk tolerance and age.

Fitted model and estimation results: We fitted the latent class model (Latent GOLD software version 4.5; Magidson and Vermunt 2005) to the 'most likely' (best) choices, using all demographic and personal characteristics to select classes for innate variability and underlying preferences. We estimated models for increasing numbers of latent scale and preference classes, selecting the preferred model using the Bayesian Schwartz information criteria (BIC), which rewards improved fit but penalizes additional parameters. ${ }^{11}$

Likelihood ratio tests of the restriction of model constancy across 2007 and 2008 are clearly rejected, indicating that the changed financial environment and/or sampling variations have a significant effect on model parameters. Although the class and variability structures of the two models are estimated as similar, we observe a greater level of general variability in the 2008 responses, and significant differences in the choices of some latent class groups, so we present results from each model separately.

Scale classes - variance heterogeneity: Variance heterogeneity in the estimated model is explained by age and the risk score from the risk profiling questionnaire (Table 9). The BIC model selection criterion indicated two scale classes where $\lambda_{1}=1$ (by normalization) and $\hat{\lambda}_{2,2007}$ $=3.37, \hat{\lambda}_{2,2008}=4.00$, implying that the first group show three or four times more variability in 
underlying response than the second group, and that variability of the high variance group was higher during the 2008 survey but membership size was similar. We estimated the scale factors using the multinomial logit model where the vector of covariates is comprised of an indicator for age and the individual's score from the risk profiling questionnaire. ${ }^{12}$ Tests indicated that other demographics were irrelevant. Results are set out in Table 9 showing that the high variability groups are more likely to be younger (with a lower score on the risk profile in 2007), whereas the low variability groups were older. Interestingly, the risk profiling score was irrelevant to scale class groupings in the crisis period sample of 2008, demonstrating a weaker connection between risk profiling and choice consistency during financial stress.

[Insert Table 9 here]

Latent classes - preference heterogeneity: Preference class composition is partly explained by age and household income, but as noted above, estimates are not constant between 2007 and 2008. The BIC model selection criterion indicated seven latent classes where class membership is a function of a constant, an indicator for age, and an indicator for household income. Other demographic and experience covariates were not significant when included as predictors in the latent class estimation. Estimation results for the multinomial logit latent class model is set out in Table 10 and Figure 1 shows the posterior prediction of scale and preference class membership by number of respondents.

[Insert Table 10 here]

In the 2007 calm period sample, preference classes 2 and 7 are more likely to include people under 25 years whereas people in classes 3, 4 and 5 are likely to be 45 years and over. Class 1 includes low income respondents and classes 4 and 5 includes high income respondents, 
whereas classes 3 and 4 have a significant chance of including those who refuse to report their income. Nearly half the sample is classified as members of classes 4 and 5 and over one quarter are in classes 2 and 7. Classes 2, 3 and 7 have a greater proportion of high-variability respondents than classes 1, 4, 5 and 6 (Figure 1).

[Insert Figure 1 here]

In the 2008 crisis period, sample class membership is less distinct. Classes 2 and 7 are again more likely to be younger, but this time the 45-65 years group is more likely to fall into class 4 and the 25-44 years group into class 5 . We find significant income effects for classes 4 and 5 (both higher income) and in classes 2 and 6, lower income. Classes 1 and 3 are estimated as distinct preference classes but their membership cannot be described using significant covariates. However, the signs of estimated coefficients indicate an older-age membership in class 3 and an older, lower-income membership in class 1 . The proportion of the sample in each of the two scale and seven preference classes are similar to the 2007 estimates (Figure 1).

Estimated preferences: The latent class model results allow us to estimate preferences for each underlying class in the sample separately, holding underlying response variability (scale) constant. We use the preference parameters to estimate the probability that the member of a particular preference and scale class will choose investment options 1 to 6 , where the conditioning information is the fee (net return of the portfolio) and the range (portfolio variance) of each option.

Table 11 shows the conditional logit estimates of choice parameters over risk and return. The top panel of Table 11 shows the underlying drivers for these choices in the calm of 2007 and the second panel shows coefficients for the crisis period of 2008. We also can compute posterior 
probabilities that members of each preference class choose particular options. The graphs in Figure 2 show (for the high variability scale class with $\lambda=1$ ) the implied choice probabilities for each investment option conditioning on preference for the calm and crisis period surveys. In both calm and crisis, results for the low variability class were similar but show choice probabilities more concentrated at the most preferred option for each preference group.

[Insert Table 11 here]

In the calm of 2007, older respondents preferred high share exposures in general, and the higher income group of older respondents tend to choose the class with $75 \%$ shares. Classes which include more young respondents divided into a conservative group (class 2) who prefer mainly cash (75:25 cash/shares mix) and a more risk tolerant group (class 7) who prefer equity weights above $50 \%$. The low income groups were most likely to choose the very conservative options of $100 \%$ cash (class 1) and the RSA (class 6).

[Insert Figure 2 here]

In 2008 most of these patterns remained. Older, higher income groups (classes 4 and 5) still chose options 4 and 5 with share exposures at $75 \%$ or $100 \%$. Low income groups (preference classes 2 and 6) preferred conservative options (75\% cash or RSA). Younger respondents again divide into cash-preferring and share-preferring groups (classes 2 and 7).

Overall, in both surveys, riskier choices are associated with older age and higher income and options with higher cash allocations with younger and lower income respondents.

Marginal effects: Our model allows us to estimate marginal changes in choice probabilities with respect to changes in net return and portfolio variance. Consistent with the risk 
parameters we inferred from the observed investment choices, analysis of marginal effects shows that a significant group of respondents make risk loving choices, and only a subset choose consistently with mean variance theory, preferring higher returns and lower risk.

Table 12 shows the change in the probability of choosing an investment option given a one percentage point (100 basis point) increase in the net annual return and a five percentage point (500 basis point) increase in the annual volatility of that investment option. Only significant marginal effects are reported. The bold typeface indicates the investment option most often chosen by the relevant preference class. For example, in the calm of 2007, (under preference class 2) if the net return to the 75:25 cash:shares option rises by one percentage point, the probability that members of class 2 will choose that option rises by $12 \%$. Similarly if the volatility of the 75:25 option rises by five percentage points, class 2 members are $8 \%$ less likely to choose it.

There are some surprising results here. Looking at 2007, we see first that preference class 1 responds negatively to higher returns. In other words, when the fees went up (and net returns fell), this group of low income respondents were more likely to choose the $100 \%$ cash option. A similar reaction is evident for preference class 6 which is the group who most often chose the bank account. In addition, no significant marginal effect was estimated for risk for these classes (about $4 \%$ of the sample) suggesting that they both always choose a conservative portfolio and do not consider risk and return at all. By contrast, the two preference classes inhabited predominantly by younger people, classes 2 and 7 ( $26 \%$ of the sample) do as theory predicts and prefer higher returns, but dislike risk, with class 7 reacting very negatively to increased risk. Thirdly, the older and higher income members of preference classes 4 and 5 tend to risk loving choices. The probability that they choose an option increases as the range of possible returns 
widens and the class 5 group react very positively to more risk. Class 4 includes about one fifth of the sample, and class 5 around one third of the respondents, implying that around half the sample make risk loving choices. Finally, class 3, which has $15 \%$ of respondents, seems to prefer the 50:50 option, responding to higher returns, but largely unresponsive to changes in risk.

Analysis of the marginal effects for the 2008 crisis sample suggest that the underlying behavioral themes stay fairly constant with consistent mean-variance preferences for the latent classes with more young respondents and risk-loving choices for the older higher income individuals. Classes 4 and 5 appeared slightly less favorable to increased risk, and class 7 somewhat less risk averse.

[Insert Table 12 here]

Cross effects: The structure of the latent class model also allowed us to estimate crosseffects; the percentage change in the probability of choosing an investment option given a change in net return or variance for one of the other investment options. Table 13 sets out a subset of these cross effects - that is, those relating to the investment option that is most commonly chosen by each preference class, marked in the table by the double asterisks.

Nearest options are frequently viewed as substitutes. Members of preference class 2, for example (mainly young respondents) tended to prefer higher returns and less risk, choosing the 75:25 cash to shares weighting most. Column 2 in Table 13 shows that members of class 2 regard the 100\% cash and 50:50 portfolios as substitutes for their preferred 75:25 option, lowering their probability of choosing the $75: 25$ portfolio by $3 \%$ when the $50: 50$ portfolio net return increases by one percentage point. In 2007, this substitution effect with the next-nearest 
portfolio is evident for preference classes 2-4 and 7 for returns. In 2008, the cross-effect in returns shows up for classes $2,4,5$ and 7 though the sign is unexpectedly positive for class 7 .

A similar comparison applies to variance cross-effects but this time the sign of the effect is conditional on whether the preference class makes risk averse or risk loving selections. In the 2007 survey, there are significant positive variance cross-effects with the next-nearest portfolio for class 7, which displays risk aversion, so that if the nearby portfolio is riskier, the respondent substitutes toward the asterisked option. There are significant negative variance cross-effects for classes 3, 4 and 5, showing that these respondents are more likely to move away from the asterisked option if the variance of the nearby portfolios rises. The 2008 model shows consistently-signed nearby variance cross-elasticities for classes 1, 4, 5 and 7 . But substitution effects are generally smaller in 2008 .

[Insert Table 13 here]

\section{Discussion}

Individual retirement savings accounts are vulnerable to large financial shocks, as the recent crisis has shown. Here we have investigated the effect of a switch from tranquil (early 2007) to crisis (late 2008) conditions on risk attitudes of, and allocation decisions by, retirement savers using a repeated choice experiment.

Pre-screening of survey respondents showed little change in risk indicators between the tranquil and crisis periods, with almost identical scoring on a financial planners' risk profiling questionnaire. Similarly, observed experimental choices showed a continued strong, though somewhat moderated, preference for riskier investments in the crisis period of 2008 . Best 
choices allocated to options with $75 \%$ or more in shares fell to $53 \%$ in 2008 , from over $60 \%$ in 2007 , largely in favor of the 50:50 allocation, and the 100\% share option attracted 6 percentage points more worst choices.

Risk parameters inferred from best and worst choices for a subset of respondents indicated most were risk-seeking during both the calm of 2007 and the financial crisis of 2008, although both best and worst choice showed an increase in the mean risk parameter in 2008, over 2007. Interestingly, the correlation between inferred risk preferences and the questionnaire scores was significant and negative for both best and worst choices, indicating that many respondents exhibited stated preferences at odds with their risk profiles.

Despite similarities, likelihood ratio tests of the restriction of estimated latent class model constancy are clearly rejected, indicating that the changed financial environment and/or sampling variations have a significant effect. The 2008 estimated model showed a greater level of general response variability. Age and income are important determinants of preference class (and therefore investment choices) for both models, while variability (scale) was determined largely by age and (in 2007) risk tolerance. The risk score (obtained from the risk profiling questionnaire) is irrelevant to scale class groupings in 2008, suggesting a weaker connection between risk profiling and choice consistency during the period of financial stress.

Preferred choices by preference class membership were similar. Classes populated by older and high income retirement savers tended to choose the riskier options, while low income and younger groups preferred the high cash options. However, in the 2008 crisis period the young risk tolerant group modified its preference away from $100 \%$ stocks. 
The underlying behavioral impacts indicated by the estimated marginal effects were very similar in both periods, with older and high income classes making risk-seeking choices and young respondents choosing consistently with mean-variance theory, with a slightly lower response to increased risk by older and high income respondents evident in the 2008 crisis period. Estimation of marginal cross effects indicate significant substitution effects (with the next-nearest investment option on the choice menu) for most preference classes in both periods, with a smaller effect in 2008, indicating less substitution with options with similar risk-return characteristics during the financial crisis.

Overall, comparing results between the relatively tranquil asset market conditions of early 2007, and the full-blown financial crisis of late October 2008 suggests a mild moderating of risk tolerance, with a slight decrease in the preference for higher share weightings.

Despite the slight moderation in risk tolerance in the crisis period, the observed choices and inferred risk preferences for both periods indicate higher risk tolerance than suggested by the risk profiling questionnaire completed by each respondent, and a greater preference for high share-weighting investment options than seen in practice - although experimental studies indicate that greater risk aversion in relation to real world decisions should not be surprising (Vlaev, Stewart \& Chater 2008). The asset allocation of the typical Australian retirement saver tends to comprise around $65 \%$ risky assets (APRA 2009), while $63(53) \%$ of 'best' choices in the 2007(2008) sample were allocated to options with $75 \%$ or more in shares.

There are a number of explanations for this result. It is possible that the respondents with high risk tolerance may be motivated by wealth and human capital characteristics for which we have incomplete information. For example, the respondents may be homeowners, have no 
household debt and have valuable stocks of low risk human capital motivating high exposure to risk (Viceira 2007).

Another factor driving our results could be experimental design. In our experiment the investment choices were restricted to a retirement savings account and 5 cash/shares portfolios ranging from $100 \%$ cash to $100 \%$ shares. Since we limited the investment choices to 'long only' investments (as does the Australian retirement savings system) some respondents may have found the $100 \%$ shares portfolio a binding constraint and preferred more risk than offered on the investment choice menu. Other possibilities include that some wealthier participants may have viewed the $\$ 1,000$ contribution as small relative to wealth or income and decided that speculation with a small additional amount is optimal (Shefrin and Statman 2000); or that the hypothetical \$1,000 contribution is a 'windfall' and therefore part of a different mental account to current income (Shefrin and Thaler 1988).

Finally, a key feature of our experimental design which may be important is the presentation of risk as a range of terminal wealth values in terms of best and worst case scenarios. This presentation differs from typical risk presentations in retirement savings fund prospectuses which tend to emphasize downside risk only, but was found to be the best risk presentation in Vlaev et al. (2009). We plan to investigate the presentation of key investment choice decision tools such as menu composition, risk presentation and links to retirement saving accumulations and other wealth in future work. 
RETIREMENT INVESTOR RISK TOLERANCE IN CRISIS AND CALM 


\section{Appendix 1: Survey Introduction}

We would like you to think about having $\$ 1,000$ to invest in your superannuation fund. The $\$ 1,000$ might come to you as a tax refund, a bonus, an inheritance, a small lottery prize, or perhaps you find an envelope with cash in it. You are required to choose the way your money is invested from a menu of investment options. We are going to show you 16 scenarios for your superannuation investment. The scenarios differ by the range of possible returns on your investment in each option and the fees you have to pay to the people managing your investment.

What we want you to do is simple. In each scenario, tell us:

- Which investment option you would be most likely to choose; and

- Which investment option you would be least likely to choose.

The accumulation in the superannuation fund will be available to you to help fund your retirement once you have reached the age at which government regulations allow you to use money from your superannuation account. This will be somewhere between 55 to 60 years, depending on your current age.

\section{Investment Options}

We will offer you a menu of six investment options. The six options include five options made up of different combinations of "cash" and "Australian shares". Australian shares is an investment in the Australian stock market. Cash is an investment in the short term money market. The sixth option is a "Retirement Savings Account", which is similar to an ordinary bank account. 
To help you make your choices we will give you information about past performance and fees for each of the six options.

As you probably are aware, however, past performance does not guarantee future results.

\section{Performance and Investment Risk}

Each investment option has a different expected accumulation (the amount that your $\$ 1,000$ will probably grow to over 10 years), and a different amount of investment risk (variation in the amount your investment grows). Different proportions of Australian shares usually result in different accumulations and risk. Historically, Australian shares have produced a higher return, but more investment risk compared with cash. Some years, share investments gain value rapidly, but some years they lose value. A Retirement Saving Account pays a fixed interest rate that is much lower than you should expect from investing in "cash" without any year by year variation.

In each scenario, for each investment option, you will see the expected (average) accumulation after the next 10 years, based on past experience of the Australian money and share markets. All dollar amounts are quoted in "real terms". That means they are adjusted for inflation and measured in 2007 dollars. The dollar amounts are totals before fees are deducted.

You will also see the likely amount of investment risk for each investment option by the range of the accumulation in your superannuation account after 10 years. The accumulation range is expressed as "likely worst case accumulation value after 10 years" and "likely best case accumulation value after 10 years". As before, these dollar amounts are based on past experience and are in 2007 dollars, without fees deducted. 


\section{Investment Management Fees}

Fees will be charged for investing your superannuation.

The investment management fee is a fee for managing the investment in your superannuation account. Investment management fees range from $1.75 \%$ per year to $2.60 \%$ per year and depend on the investment option you choose. There are no investment management fees on the Retirement Savings Account.

Now, we will show you 16 scenarios that contain the six investment options. Please evaluate each scenario carefully before making a choice about where to invest your $\$ 1000$. 


\section{Appendix 2: Modelling and Estimation Approach}

In a McFadden (1974) conditional logit model, the random utility of choosing investment option $j$ for individual $i$ is

$$
U_{i j}^{*}=V_{i j}+\varepsilon^{*}{ }_{i j}
$$

where $\varepsilon_{i j}^{*}$ is i.i.d. extreme value with variance $\left(\left(\pi^{2}\right) /\left(6 \lambda^{2}\right)\right)$, where $\lambda$ is a scaling factor commonly set to one. The probability that individual $i$ chooses investment option $j$ is

$$
\begin{aligned}
P_{i j} & =\operatorname{Pr}\left(V_{i j}+\varepsilon_{i j}^{*}>V_{i k}+\varepsilon_{i k}^{*}, \forall k \neq j\right) \\
& =\operatorname{Pr}\left(\varepsilon_{i k}^{*}<\varepsilon_{i j}^{*}+V_{i j}-V_{i k}, \forall k \neq j\right)
\end{aligned}
$$

and

$$
P_{i j}=\frac{\exp \left(\beta_{j}^{* \prime} x_{i j}\right)}{\sum_{j} \exp \left(\beta_{j}^{* \prime} x_{i j}\right)} .
$$

where $x_{i j}$ is a vector comprised in our model of a constant for option $j$, portfolio return net of fees and the RSA return, and portfolio variance for option $j$. Since the model depends on comparisons of $U^{*}{ }_{i j} \mathrm{~s}$ and choices are therefore invariant to the scale of utility, it is conventional to reweight utility by $\lambda$ so as to set the variance of the unobserved component of utility to var( $\left.\varepsilon_{i j}^{*}\right)=\lambda^{2}\left(\pi^{2} / 6 \lambda^{2}\right)=\pi^{2} / 6$, and

$$
P_{i j}=\frac{\exp \left(\lambda \beta_{j}^{* \prime} x_{i j}\right)}{\sum_{j} \exp \left(\lambda \beta_{j}^{* \prime} x_{i j}\right)}=\frac{\exp \left(\beta_{j}^{\prime} x_{i j}\right)}{\sum_{j} \exp \left(\beta_{j}^{\prime} x_{i j}\right)},
$$


where $\beta=\lambda \beta^{*}$. The variance scaling factor $\lambda$ and preference parameter vector $\beta^{*}$ are always jointly estimated, so interpretation depends on the normalization chosen for $\lambda$. In a finite mixture model such as we estimate here, if we allow the preference parameters $\beta^{*}$ to vary between latent classes of investors, but restrict $\lambda=1$ for all classes, then there is always a danger of interpreting differences in $\beta$ by class as due to $\beta^{*}$ when they are caused by differences in $\lambda$.

In a generalized latent class model, ${ }^{\text {xii }}$ the random utility of option $j$ for individual $i$ is dependent on the latent preference class $q=1, \ldots, Q$ and the unobserved scale parameter class $\lambda_{d}$, $d=1, \ldots, D$ inhabited by individual $i$. (We normalize one scale parameter to one and interpret the others as ratios to the normalized value.) The probability of choice $j$ by individual $i$ in choice situation $t$, conditioning on class $q$ and scale factor class $d$ is

$$
P(i, t, j \mid q, d)=\frac{\exp \left(\lambda_{d} \beta_{q, j}{ }^{\prime} x_{i t, j}\right)}{\sum_{j} \exp \left(\lambda_{d} \beta_{q, j}{ }^{\prime} x_{i t, j}\right)}
$$

and $\lambda_{d}=1 \mid d=1$,

$$
P(i, t, j \mid q, d=1)=\frac{\exp \left(\beta_{q, j}{ }^{\prime} x_{i t, j}\right)}{\sum_{j} \exp \left(\beta_{q, j}{ }^{\prime} x_{i t, j}\right)} .
$$

For simplicity we write

$$
P_{i t \mid q, d}=\operatorname{Pr}\left[y_{i t}=j \mid \text { class }=q, \text { scale }=d\right] .
$$

If each of the $t=1, \ldots, T$ choice events are independent, then the contribution of the individual $i$ to the overall likelihood, conditioning on class and scale is 


$$
P_{i \mid q, d}=\prod_{t=1}^{T} P_{i t \mid q, d}
$$

We assume that there are $Q$ discrete latent classes and $D$ scale groupings, but that class membership is hidden. The best estimated models in our study have $Q=7$ latent preference classes and $D=2$ scale groups, and we allow for the classes to be determined using a set of observable characteristics or demographics. If $H_{i q \mid d}$ is the prior probability for class $q$ for individual $i$ and $G_{i q \mid d}$ is the prior probability for scale group $d$, then the multinomial logit model suggested by Greene and Hensher (2003) can be used to estimate each prior as:

$$
H_{i q \mid d}=\frac{\exp \left(\theta_{q}^{\prime} z_{i}\right)}{\sum_{q} \exp \left(\theta_{q}^{\prime} z_{i}\right)}, G_{i d}=\frac{\exp \left(\gamma_{d}{ }^{\prime} z_{i}\right)}{\sum_{q} \exp \left(\gamma_{d}^{\prime} z_{i}\right)} .
$$

The vector $z_{i}$ includes $k=1, \ldots, K$ relevant covariates and/or demographic characteristics of individual $i$ including a constant. In our estimated models, the set of demographics $\left(z_{i}\right)$ is comprised of indicators for the age and household income of respondents, and their risk score from the risk profiling questionnaire. These demographics decide the composition of the 7 latent preference and 2 scale classes, but in the final models reported in Tables 9 and 10 not all of these demographic variables are selected.

To ensure complete allocation of all individuals to a preference and scale class, we have $\sum_{q} \theta_{k, q}=0$ and $\sum_{d} \gamma_{k, d}=0$. If none of the variables in $z_{i}$ are relevant, then the $H_{q \mid d}$ and $G_{d}$ reduce to a $Q(D)$-vector of constants which sum to one. Combining these together, the overall $\log$ likelihood is 


$$
\ln L=\sum_{i=1}^{N} \ln P_{i}=\sum_{i=1}^{N} \ln \left[\sum_{d=1}^{D} \sum_{q=1}^{Q} G_{i d} H_{i q \mid d} P_{i \mid q, d}\right]=\sum_{i=1}^{N} \ln \left[\sum_{d=1}^{D} \sum_{q=1}^{Q} G_{i d} H_{i q \mid d} \prod_{t=1}^{T} P_{i t \mid q, d}\right] .
$$

Estimation of the parameters of the model is by numerical maximization of the log likelihood. Following the Latent GOLD default estimation process, we use 10 randomized sets of starting values and small Bayes constants to try to ensure that an identified global maximum is reached. We choose the number of preference and scale classes using the Bayesian Information Criterion, $\mathrm{BIC}=\ln L+($ model size $\ln N) /(\ln N)$.

The posterior probability that an individual belongs to preference class $q$ can be inferred from Bayes theorem and the estimated parameters where

$$
\hat{H}_{q \mid i}=\frac{\sum_{d} P_{i \mid q, d} \hat{H}_{i q \mid d} \hat{G}_{i d}}{\sum_{q} \sum_{d} P_{i \mid q, d} \hat{H}_{i q \mid d} \hat{G}_{i d}}
$$

and similarly for scale class $d$ where

$$
\hat{G}_{d \mid i}=\frac{\sum_{q} P_{i \mid q, d} \hat{H}_{i q \mid d} \hat{G}_{i d}}{\sum_{q} \sum_{d} P_{i \mid q, d} \hat{H}_{i q \mid d} \hat{G}_{i d}} .
$$

Another restriction of the conventional conditional logit model is that of the independence of irrelevant alternatives (IIA) where an increase in the odds of choosing a particular option $j$ implies a proportional decrease in all other probabilities, so that odds ratios not directly impacted by the changes for option $j$ stay constant. In other words the model treats all alternatives as proportionately substitutable, and does not allow for different degrees of substitutability and complementarity. This seems unlikely where the alternatives include choices that are close substitutes as is the case in our experiment. Consequently a real advantage of the latent class 
model here is that IIA does not hold: in equation (A2.9) all variables appear in the probability $P_{i t \mid q, d}$, including those of different alternatives.

The marginal effect on individual $i$ 's choice probability for option $j$ in choice situation $t$ due to a change in attribute $m$ in option $w$ is

$$
\hat{\sigma}_{i t, m, j, w \mid q, d}=\frac{\partial P(i, t, j \mid q, d)}{\partial x_{i t, m, w}}=\left[1(w=j)-P(i, t, j \mid q, d) P(i, t, w \mid q, d) \beta_{m, w \mid q, d}\right]
$$

which can be averaged across individuals and choice sets. 


\section{References}

Agnew, J. R., \& Szykman, L. R. (2005). Asset Allocation and Information Overload: The Influence of Information Display, Asset Choice and Investor Experience. Journal of Behavioral Finance, 6:2, 57-70.

Ameriks, J., \& Zeldes, S. P. (2004). How do Household Portfolio Shares Vary with Age? Working Paper, Columbia University.

Antolin, P., \& Stewart, F. (2009). Private Pensions and Policy Responses to the Financial and Economic Crisis. OECD Working Papers on Insurance and Private Pensions No. 36.

Australian Prudential Regulatory Authority. (2009). Superannuation Fund-Level Rates of Return, December 2008 (released 20th August 2009), Canberra.

Bateman, H., Louviere, J. J., Thorp, S., Islam. T. \& Satchell, S. (2009). An experimental survey of investment decisions for retirement savings, forthcoming, Journal of Consumer Affairs.

Bell, D. E. (1982). Regret in decision making under uncertainty. Operations Research, 30, 961981.

Benartzi, S., \& Thaler, R. H. (1995). Myopic loss aversion and the equity premium puzzle. Quarterly Journal of Economics, February, 73-92.

Benartzi, S., \& Thaler, R. H. (2001). Naïve diversification strategies in defined contribution saving plans. American Economic Review, 91(1), 79-97.

Benartzi, S., \& Thaler, R. H. (2007). Heuristics and biases in retirement savings behavior. Journal of Economic Perspectives 21(3), 81-104. 
Benartzi, S., Peleg. E., \& Thaler, R. H. (2009). Choice Architecture and Retirement Saving Plans, Working Paper, Anderson School, UCLA. http://ssrn.com/abstract=999420.

Clark, G. L., \& Strauss, K. (2008). Individual Pension-Related Risk Propensities: the Effect of Socio-demographic Characteristics and a Spousal Entitlement on Risk Attitudes. Ageing and Society, 28, 847-74.

Copeland, C. (2009). Individual Account Retirement Plans: An Analysis of the 2007 Survey of Consumer Finances, with Market Adjustments to June 2009, EBRI Issue Brief, no. 333, August.

Fiebig. D., Keane, M. D., Louviere, J. J., \& Wasi, N. (2009). The Generalized Multinomial Logit Model: Accounting for Scale and Coefficient Heterogeneity. CenSoc Working Paper No. 09-002. University of Technology, Sydney.

Gerrans, P., \& Clark-Murphy, M. (2004). Gender Differences in Retirement Savings Decisions. Journal of Pension Economics and Finance, 3(1), 145-164.

Greene, W. H., \& Hensher, D. A. (2003). A latent class model for discrete choice analysis: contrasts with mixed logit. Transportation Research Part B: Methodological, 37, 681698.

Hallahan, T., Faff, R., \& McKenzie, M. (2003). An Exploratory Investigation of the Relation between Risk Tolerance Scores and Demographic Characteristics. Journal of Multinational Financial Management, 13, 483-502.

Holt, C. A., \& Laury, S. K. (2002). Risk Aversion and Incentive Effects. The American Economic Review, 92(5), 1644-1655. 
Huberman, G., \& Jiang, W. (2006). Offering versus choice in 401(k) plans: equity exposure and number of funds. Journal of Finance, 56(2), 763-801.

Kahneman, D., \& Riepe, M. (1998). Aspects of investor psychology: Beliefs preferences and biases in investment advisors should know about. Journal of Portfolio Management, 24(4), 52-65.

Loomes, G., \& Sugden, R. (1982). Regret theory: an alternative theory of rational choice under uncertainty. Economic Journal, 92, 805-824.

Louviere, J. J., \& Eagle, T. (2006). Confound it! That pesky little scale constant messes up our convenient assumptions, Sawtooth Software Conference 2006, Florida, USA, March 2006 in Proceedings of the Sawtooth Software Conference 2006, ed., Sawtooth Software Inc, Sequim, USA, 211-228.

Louviere, J. J., Hensher, D. A., \& Swait, J. D. (2000). Stated Choice Methods, Cambridge University Press.

Magidson, J., \& Vermunt, J. K. (2005). Technical Guide to Latent Gold Software 4.5. Statistical Innovations.

McFadden, D. (1974). Conditional logit analysis of qualitative choice behavior. In P. Zarembka, ed., Frontiers in Econometrics. New York: Academic Press.

Michenaud, S., \& Solnik, B. (2008). Applying regret theory to investment choices: a currency hedging approach. SSRN: http://ssrn.com/abstract=676728.

Sherfin, H., \& Statman, M. (2000). Behavioral Portfolio Theory. Journal of Financial and Quantitative Analysis, 35(2), 127-151. 
Sherfin, H., \& Thaler, R. D. (1988). The Behavioral Lifecycle Hypothesis. Economic Inquiry, 26(4), 609-643.

Speelman, C., Clark-Murphy, M., \& Gerrans, P. (2007). Decision Making Clusters in Retirement Savings: Preliminary Findings. Australian Journal of Labour Economics, 10(2), 115-127.

Tversky, A., \& Kahneman, D. (1974). Judgement under Uncertainty: Heuristics and Biases. Science, 185, 1124-1131.

Viceira, L. M. (2007). Life-Cycle Funds. Working Paper, Harvard Business School, Harvard University. Available at SSRN: http://ssrn.com/abstract=988362.

Vlaev. I., Stewart, N., \& Chater, N. (2008). Risk Preference Discrepancy: A Prospect Relativity Account of the Discrepancy Between Risk Preferences in Laboratory Gambles and Real World Investments. Journal of Behavioral Finance, 9:3, 132-148.

Vlaev. I., Chater, N., \& Stewart, N. (2009). Dimensionality of Risk Perception: Factors Affecting Consumer Understanding and Evaluation of Financial Risk. Journal of Behavioral Finance, 10:3, 158-181.

Yooks, K. C., \& Everett, R. E., (2003). Assessing risk tolerance: Questioning the questionnaire method. Journal of Financial Planning 16(8), 48-55. 
FIGURE 1 Posterior prediction of scale and preference class membership 2007

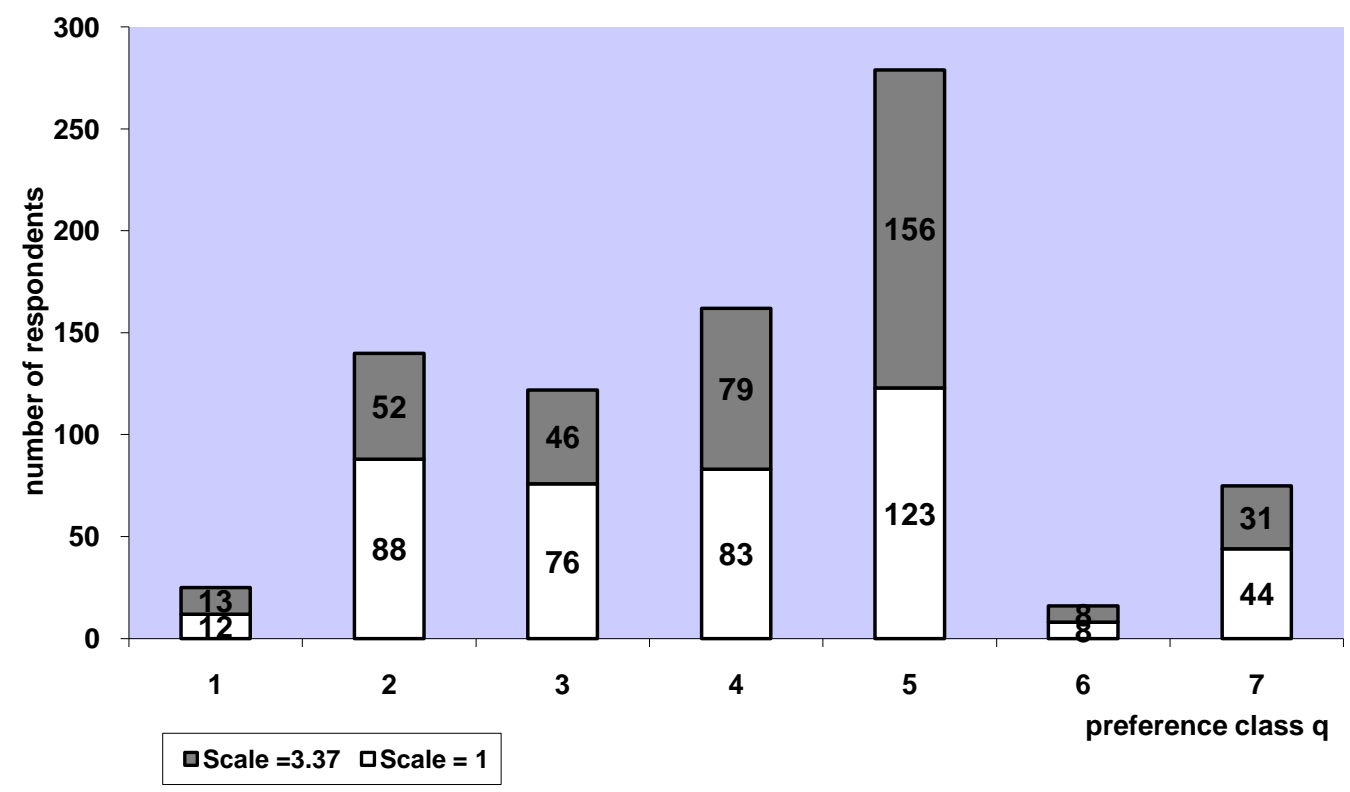

2008

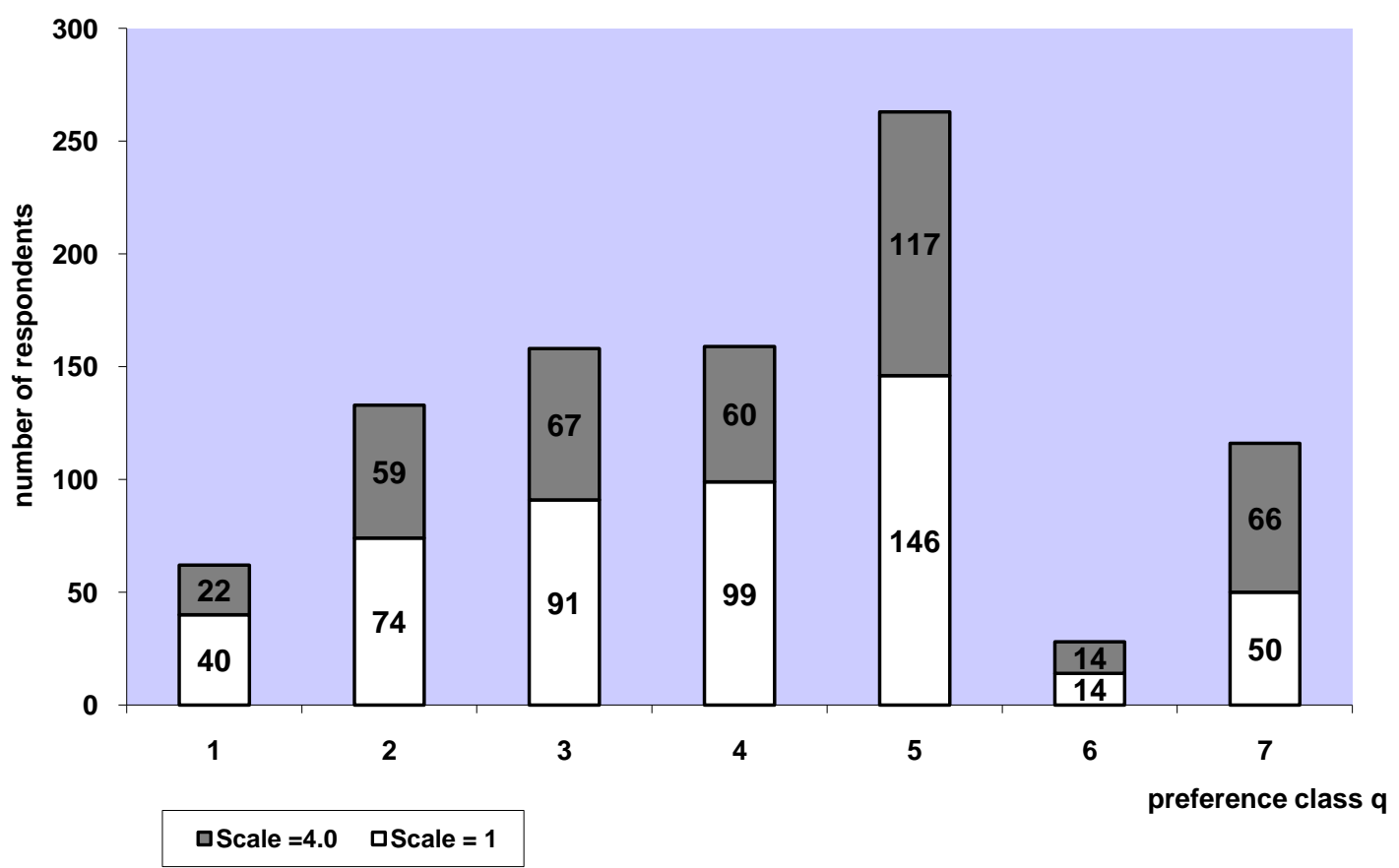


FIGURE 2 Investment choice probabilities by preference class 2007

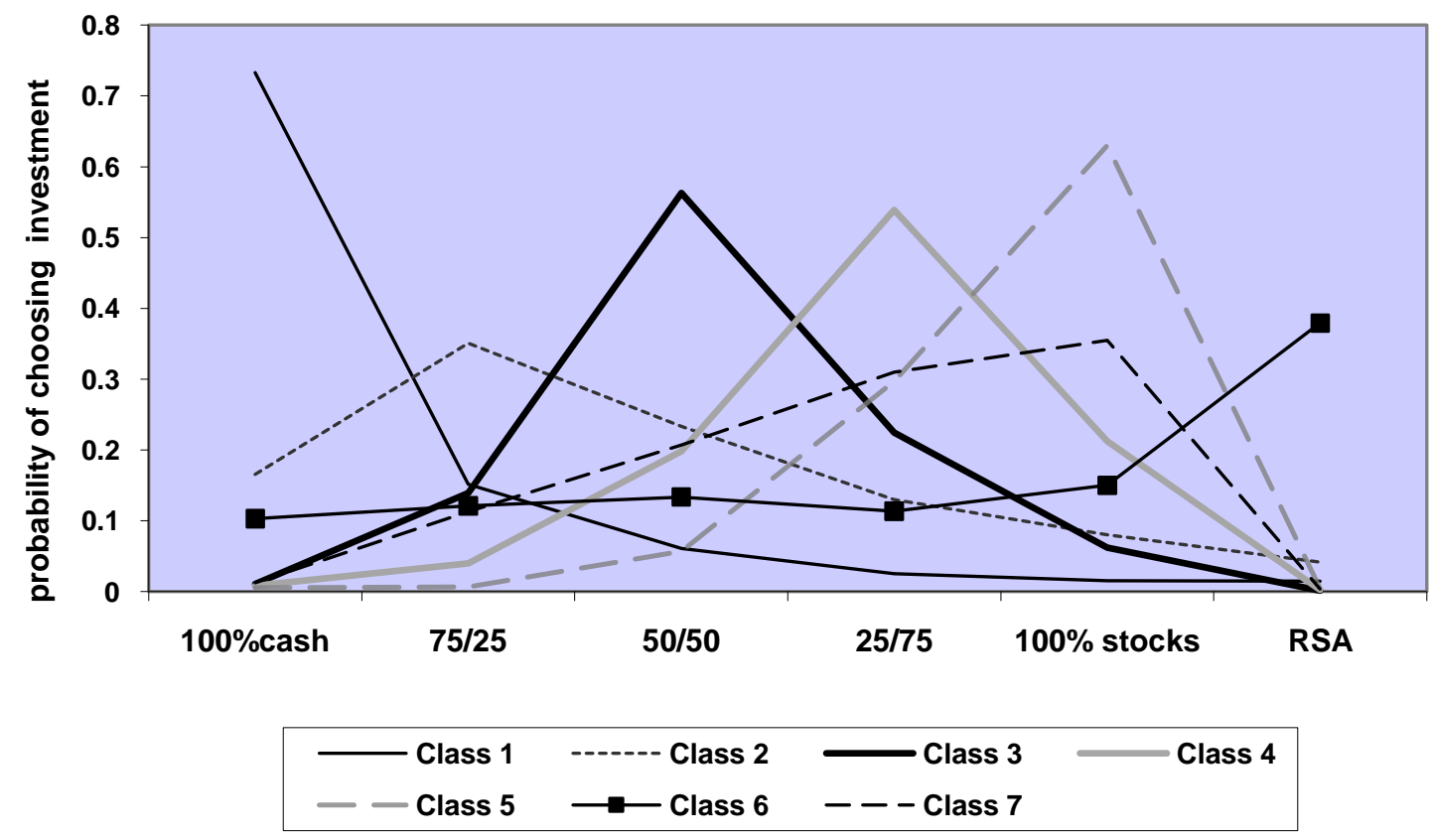

2008

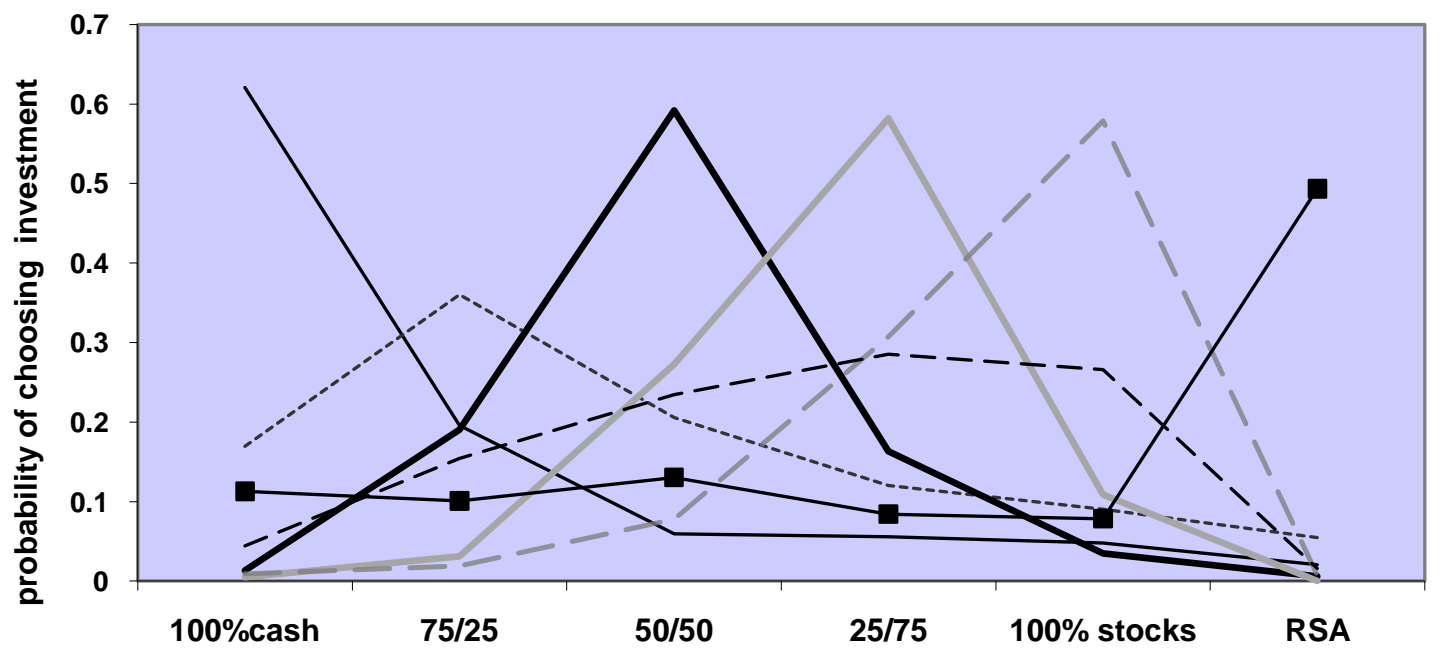

\begin{tabular}{rrr}
\hline Class 1 & $-\cdots--$ Class 2 & - Class 3
\end{tabular} Class 4

Note: Graphs show estimated average probability $P(j / q, d)$ of choice of investment option $j$ for each preference class where scale parameter $\lambda=1$. 
TABLE 1 Demographic and personal characteristics, \% of sample

\begin{tabular}{|c|c|c|c|c|c|}
\hline Characteristic & 2007 & 2008 & Characteristic & 2007 & 2008 \\
\hline Gender & & & Occupation & & \\
\hline Female & 50 & 49 & Professional & 24 & 20 \\
\hline Male & 50 & 51 & Manager & 10 & 12 \\
\hline Age & & & Administrator & 9 & 10 \\
\hline $18-24$ years & 14 & 12 & Small business owner & 6 & 6 \\
\hline 25-34 years & 31 & 25 & Sales & 6 & 5 \\
\hline $35-44$ years & 23 & 22 & Clerical/service worker & 12 & 12 \\
\hline $45-54$ years & 19 & 20 & Transport worker & 2 & 2 \\
\hline $55-64$ years & 13 & 10 & Labourer & 3 & 4 \\
\hline 65 years and over & 0.2 & 0 & Tradesperson & 4 & 5 \\
\hline Marital status & & & Home duties & 12 & 11 \\
\hline Single & 28 & 25 & Retired & 7 & 7 \\
\hline Living with partner & 9 & 9 & Unemployed & 5 & 4 \\
\hline Married/de facto & 54 & 57 & Household income & & \\
\hline Widowed & 2 & 2 & $>\$ 40,000$ & 15 & 14 \\
\hline Separated/divorced & 7 & 8 & $\$ 40,001-\$ 90,000$ & 36 & 35 \\
\hline Children under 18 - Yes & 41 & 42 & $\$ 90,001-\$ 150,000$ & 24 & 24 \\
\hline Age of children & & & $\$ 150,001-\$ 210,000$ & 7 & 9 \\
\hline $0-2$ years & 31 & 31 & $\$ 210,001-\$ 240,000$ & 1 & 1 \\
\hline $3-5$ years & 28 & 26 & Over $\$ 240,000$ & 3 & 2 \\
\hline $6-9$ years & 31 & 34 & Prefer not to say & 15 & 15 \\
\hline $10-14$ years & 39 & 33 & Homeowner & 56 & 55 \\
\hline $15-18$ years & 27 & 30 & Car owner & 88 & 89 \\
\hline Education & & & Investment property & 19 & 17 \\
\hline Some secondary & 8 & 9 & Non retirement investment & & \\
\hline 4 years secondary & 11 & 10 & Yes & 68 & 68 \\
\hline High School Graduate & 17 & 17 & No, but considering & 25 & 23 \\
\hline Technical/trade certificate & 20 & 24 & No, not interested & 7 & 9 \\
\hline University (undergraduate) & 27 & 24 & Non retirement shares & & \\
\hline Other college & 7 & 4 & Yes & 43 & 41 \\
\hline University (postgraduate) & 11 & 13 & No, but considering & 41 & 31 \\
\hline Employment status & & & No, not interested & 16 & 28 \\
\hline Full time & 52 & 52 & Property & 23 & 20 \\
\hline Part time & 21 & 20 & Shares & 42 & 41 \\
\hline Not working & 22 & 24 & Managed funds & 21 & 20 \\
\hline \multirow[t]{7}{*}{ Full time student } & 5 & 4 & Savings accounts & 80 & 82 \\
\hline & & & Attitudes to risk & & \\
\hline & & & Conservative & 2 & 3 \\
\hline & & & Moderately conservative & 18 & 17 \\
\hline & & & Balanced & 76 & 76 \\
\hline & & & Moderately aggressive & 4 & 4 \\
\hline & & & Aggressive & 0 & 0.2 \\
\hline
\end{tabular}

Note: Demographic characteristics and risk profiling survey responses of sample of 819 individuals in

March 2007 and 919 individuals in October 2008 from PureProfile web panel. 
TABLE 2 Attribute levels

\begin{tabular}{lccccccc}
\hline Key Features & & $100 \%$ cash & $\begin{array}{c}75 \% \text { cash } \\
25 \% \text { shares }\end{array}$ & $\begin{array}{c}50 \% \text { cash } \\
50 \% \text { shares }\end{array}$ & $\begin{array}{c}25 \% \text { cash } \\
75 \% \text { shares }\end{array}$ & $100 \%$ shares & $\begin{array}{l}\text { Retirement } \\
\text { Savings } \\
\text { Account }\end{array}$ \\
& & & & & & & \\
\hline Risk & 1 & $1450-2000$ & $1300-3050$ & $1100-4000$ & $800-8400$ & $600-15800$ & 1140 \\
Range of terminal & 2 & $1500-1850$ & $1500-2450$ & $1350-3400$ & $1200-4700$ & $1000-6250$ & 1140 \\
wealth values & 3 & $1550-1800$ & $1600-2350$ & $1550-3150$ & $1400-4100$ & $1300-5350$ & 1140 \\
& 4 & $1600-1750$ & $1700-2200$ & $1750-2800$ & $1700-3500$ & $1700-4300$ & 1140 \\
Portfolio standard & 1 & $1.7 \%$ & $5.1 \%$ & $8.2 \%$ & $12.7 \%$ & $17.4 \%$ & $0 \%$ \\
deviations p.a. & 2 & $1.5 \%$ & $3.7 \%$ & $7.0 \%$ & $10.3 \%$ & $13.9 \%$ & $0 \%$ \\
& 3 & $1.2 \%$ & $3.2 \%$ & $5.8 \%$ & $8.8 \%$ & $11.5 \%$ & $0 \%$ \\
& 4 & $0.8 \%$ & $2.23 \%$ & $4.1 \%$ & $6.3 \%$ & $8.0 \%$ & $0 \%$ \\
\hline Returns & & & & & & & \\
10 yr value in & & $\$ 1675$ & $\$ 1950$ & $\$ 2250$ & $\$ 2550$ & $\$ 2800$ & 1140 \\
dollars & & $5.3 \%$ & $6.9 \%$ & $8.4 \%$ & $9.8 \%$ & $10.8 \%$ & $1.3 \%$ \\
Rate of return p.a. & & $4.0 \%$ & $5.6 \%$ & $7.1 \%$ & $8.5 \%$ & $9.5 \%$ & $0 \%$ \\
Less return on RSA & & & & & & & \\
& 1 & $1.75 \%$ & $1.90 \%$ & $1.85 \%$ & $2.25 \%$ & $2.20 \%$ & $0 \%$ \\
Investment & 2 & $2.00 \%$ & $1.95 \%$ & $2.00 \%$ & $2.30 \%$ & $2.30 \%$ & $0 \%$ \\
management & 3 & $2.10 \%$ & $2.10 \%$ & $2.20 \%$ & $2.35 \%$ & $2.40 \%$ & $0 \%$ \\
fees & 4 & $2.20 \%$ & $2.15 \%$ & $2.30 \%$ & $2.40 \%$ & $2.60 \%$ & $0 \%$ \\
& & & & & & & \\
Portfolio return & 1 & $2.25 \%$ & $3.70 \%$ & $5.20 \%$ & $6.25 \%$ & $7.30 \%$ & $0 \%$ \\
p.a. net of fees & 2 & $2.00 \%$ & $3.65 \%$ & $5.10 \%$ & $6.20 \%$ & $7.20 \%$ & $0 \%$ \\
& 3 & $1.90 \%$ & $3.50 \%$ & $4.90 \%$ & $6.15 \%$ & $7.10 \%$ & $0 \%$ \\
& 4 & $1.80 \%$ & $3.45 \%$ & $4.80 \%$ & $6.10 \%$ & $6.90 \%$ & $0 \%$ \\
\hline
\end{tabular}

Note: Returns and ranges are inflation-adjusted. For the retirement savings account (RSA), the return is the compound average \% p.a. return from the Commonwealth Bank Retirement Savings Account Product Disclosure Statement, adjusted for taxes and inflation (account balance $\$ 1000<\$ 5000$ ) and the terminal value has zero risk. Risk levels are taken from a bootstrap of historical returns and are the range of final values of $\$ 1000$ investment after 10 years, min-max, 5-95th, 10-90th and 20-80th quantile ranges rounded to the nearest $\$ 50$. Standard deviations were computed by truncating each bootstrapped empirical distribution at the required range, and then computing the annualized standard deviation for the truncated distribution. The 'expected' outcomes are the 50th quantiles for each option. Return is the median expressed as a real annualized percentage and net of the $1.3 \%$ fixed return on the retirement savings account. The last four rows show the implicit levels of net returns when management fees for each investment option are deducted. 


\section{TABLE 3 Choice set template}

Which of the following options are you most likely to choose when considering investment options?

Please tick ONE BOX for most likely and ONE BOX for least likely

\begin{tabular}{llllll}
\multicolumn{5}{l}{ Investment options for you to consider for a \$1,000 contribution } \\
\hline $100 \%$ & $75 \%$ cash & $50 \%$ cash & $25 \%$ cash & $100 \%$ & Retirement \\
cash & $25 \%$ shares & $50 \%$ shares & $75 \%$ shares & shares & Savings \\
& & & & & Account
\end{tabular}

Key Features after 10 years

\begin{tabular}{lllllll}
\hline Likely worst case accumulation & $\$ 1450$ & $\$ 1500$ & $\$ 1550$ & $\$ 1700$ & $\$ 600$ & $\$ 1140$ \\
Expected (average) accumulation & $\$ 1675$ & $\$ 1950$ & $\$ 2250$ & $\$ 2550$ & $\$ 2800$ & $\$ 1140$ \\
Likely best case accumulation & $\$ 2000$ & $\$ 2450$ & $\$ 3150$ & $\$ 3500$ & $\$ 15800$ & $\$ 1140$ \\
\hline \multirow{2}{*}{ Investment management fee (\% p.a.) } & $1.75 \%$ & $1.95 \%$ & $2.20 \%$ & $2.40 \%$ & $2.20 \%$ & $0 \%$ \\
\hline
\end{tabular}

1. Which investment option would you be most likely to choose? (tick one)

2. Which investment option would you be least likely to choose? (tick one)

Note: Table shows one example of an investment choice set offered to survey participants. Each participant chose most and least likely choices from 16 of these tables where the levels of investment management fees and likely 'worst' and 'best' case accumulation after 10 years varied over four levels for each option apart from the retirement savings account. 
TABLE 4 Observed choices of most likely (best) and least likely (worst) options

\begin{tabular}{|c|c|c|c|c|c|c|c|}
\hline \multirow[t]{2}{*}{2007} & \multicolumn{7}{|c|}{ Investment option } \\
\hline & $\begin{array}{l}100 \% \\
\text { cash }\end{array}$ & $75: 25$ & 50:50 & $25: 75$ & $100 \%$ shares & RSA & total \\
\hline \multicolumn{8}{|l|}{ best } \\
\hline choices & 700 & 1411 & 2536 & 3920 & 4300 & 237 & 13104 \\
\hline proportions & 0.05 & 0.11 & 0.19 & 0.30 & 0.33 & 0.02 & \\
\hline odds ratio $\mathrm{RSA}$ & 2.95 & 5.5 & 9.5 & 15 & 16.5 & & \\
\hline \multicolumn{8}{|l|}{ worst } \\
\hline proportions & 0.15 & 0.04 & 0.05 & 0.06 & 0.12 & 0.59 & \\
\hline odds ratio $\mathrm{RSA}$ & 0.25 & 0.07 & 0.08 & 0.10 & 0.20 & & \\
\hline \multirow[t]{2}{*}{2008} & \multicolumn{7}{|c|}{ Investment option } \\
\hline & $\begin{array}{l}100 \% \\
\text { cash }\end{array}$ & $75: 25$ & 50:50 & $25: 75$ & $100 \%$ shares & $\overline{\text { RSA }}$ & total \\
\hline \multicolumn{8}{|l|}{ best } \\
\hline choices & 1097 & 1896 & 3448 & 4014 & 3798 & 446 & 14699 \\
\hline proportions & 0.07 & 0.13 & 0.23 & 0.27 & 0.26 & 0.03 & \\
\hline odds ratio RSA & 2.46 & 4.25 & 7.73 & 9.00 & 8.52 & & \\
\hline \multicolumn{8}{|l|}{ worst } \\
\hline proportions & 0.13 & 0.04 & 0.04 & 0.06 & 0.18 & 0.56 & \\
\hline odds ratio $\mathrm{RSA}$ & 0.22 & 0.06 & 0.07 & 0.10 & 0.31 & & \\
\hline
\end{tabular}

Note: Upper rows show the observed number and proportion of best/worst investment choices for each option from the raw survey data along with the observed odds ratio relative to the retirement savings account (option 6), for 2007 survey. Lower rows show the same for 2008 survey. The 819 (919) respondents made selections from 16 choice sets generating 13104 (14699) observations each of 'most likely' and 'least likely' investment choices. In 2008, one respondent selected from 11 rather than 16 choice sets producing a total of 14699 rather than 14704 responses. 
TABLE 5 Risk parameter inference example: best choices

\begin{tabular}{|c|c|c|c|c|c|c|c|c|c|c|c|c|c|c|c|}
\hline \multirow{2}{*}{\multicolumn{2}{|c|}{$\begin{array}{l}\text { Investment } \\
\text { option }\end{array}$}} & \multirow{2}{*}{\multicolumn{2}{|c|}{$\begin{array}{c}6 \\
\text { RSA }\end{array}$}} & \multirow{2}{*}{\multicolumn{2}{|c|}{$\begin{array}{c}1 \\
\text { cash }\end{array}$}} & \multirow{2}{*}{\multicolumn{2}{|c|}{$\begin{array}{c}2 \\
75: 25\end{array}$}} & \multirow{2}{*}{\multicolumn{2}{|c|}{$\begin{array}{c}3 \\
50: 50\end{array}$}} & \multirow{2}{*}{\multicolumn{2}{|c|}{$\begin{array}{c}4 \\
25: 75\end{array}$}} & \multirow{2}{*}{\multicolumn{2}{|c|}{$\begin{array}{c}5 \\
\text { shares }\end{array}$}} & \multicolumn{2}{|c|}{ selected } \\
\hline & & & & & & & & & & & & & & $\max$ & $\min$ \\
\hline set & best & + & - & + & - & + & - & + & - & + & - & + & - & + & - \\
\hline 17 & 5 & 746 & 172 & 171 & 28 & 27 & 9 & 8 & 3 & 2 & 2 & 1 & -30 & 1 & -30 \\
\hline 18 & 4 & 746 & 172 & 171 & 45 & & & 44 & 11 & -3 & -30 & 10 & -2 & -3 & -30 \\
\hline 19 & 5 & 746 & 172 & 171 & 31 & 30 & 12 & 11 & 7 & 6 & 2 & 1 & -30 & 1 & -30 \\
\hline 20 & 5 & 746 & 172 & 171 & 30 & 29 & 20 & & & 19 & 3 & 2 & -30 & 2 & -30 \\
\hline 21 & 5 & 746 & 152 & 151 & 36 & 36 & 8 & 7 & 5 & 4 & 2 & 1 & -30 & 1 & -30 \\
\hline 22 & 4 & 746 & 152 & 151 & 42 & & & 41 & 4 & -7 & -30 & 3 & -6 & -7 & -30 \\
\hline 23 & 5 & 746 & 152 & 151 & 41 & 40 & 17 & & & 16 & 1 & 0 & -30 & $\mathbf{0}$ & -30 \\
\hline 24 & 5 & 746 & 152 & 151 & 40 & 39 & 19 & & & -9 & -30 & 18 & -8 & 18 & -8 \\
\hline 25 & 5 & 746 & 663 & 662 & 13 & & & 12 & 10 & 9 & 4 & 3 & -30 & 3 & -30 \\
\hline 26 & 5 & 746 & 663 & 662 & 39 & & & 38 & 9 & 8 & 2 & 1 & -30 & 1 & -30 \\
\hline 27 & 4 & 746 & 663 & 662 & 21 & & & & & -2 & -30 & 10 & -1 & -2 & -30 \\
\hline 28 & 5 & 746 & 663 & 662 & 14 & 13 & 8 & 7 & 6 & 5 & 1 & 0 & -30 & 0 & -30 \\
\hline 29 & 5 & 746 & 254 & 253 & 94 & 93 & 17 & & & & & 16 & -30 & 16 & -30 \\
\hline 30 & 5 & 746 & 254 & 253 & 91 & 90 & 29 & 28 & 4 & 3 & 2 & 1 & -30 & 1 & -30 \\
\hline 31 & 5 & 746 & 254 & 253 & 105 & 104 & 8 & 7 & 5 & & & 4 & -30 & 4 & -30 \\
\hline 32 & 4 & 746 & 254 & 253 & 102 & 101 & 3 & 5 & 3 & & & 2 & -30 & & \\
\hline \multicolumn{14}{|c|}{ Inferred range for risk parameter: } & -7 & -8 \\
\hline \multicolumn{16}{|c|}{$\begin{array}{l}\text { Note: Table gives an example of the } 16 \text { choice sets and 'best' or most preferred choices of one respondent in the } \\
2008 \text { survey and values of } 2 \eta \text { for which investment options } 1-6 \text { will generate maximum utility } V_{i j} \text { if the respondent }\end{array}$} \\
\hline \multirow{2}{*}{\multicolumn{16}{|c|}{ behaves consistently with a mean-variance utility function. Each choice made by the respondent implies the range }} \\
\hline & & & & & & & & & & & & & & & \\
\hline \multicolumn{16}{|c|}{ right hand cells of the table. We infer that this respondent behaves consistently with absolute risk 'aversion' between } \\
\hline
\end{tabular}


TABLE 6 Summary statistics and histogram: risk preferences for most preferred choices

\begin{tabular}{ccccccc}
\hline & & $\mathbf{2 0 0 7}$ & & & $\mathbf{2 0 0 8}$ & \\
& lower & upper & midpoint & lower & upper & midpoint \\
\hline mean & 21 & 33 & 27 & 59 & 85 & 72 \\
median & -2 & 0 & -1 & -1 & 0 & -0.5 \\
maximum & 746 & 745 & 745.5 & 745 & 746 & 745.5 \\
minimum & -30 & -29 & -29.5 & -30 & -29 & -29.5 \\
std. dev & 113 & 124 & 117 & 175 & 198 & 186 \\
observations & 122 & 122 & 122 & 108 & 108 & 108 \\
\hline
\end{tabular}

Note: Table shows summary statistics for cross-section of inferred risk parameters using consistent 'best' choices from 2007 and 2008 surveys. We report the upper and lower bounds and midpoints of the interval $\left(2 \eta_{i j}{ }^{+} 2 \eta_{i j}\right)^{*}$ whenever the risk parameter ranges imply a consistent intersection.

\section{Distributions of midpoints of risk parameter intervals}

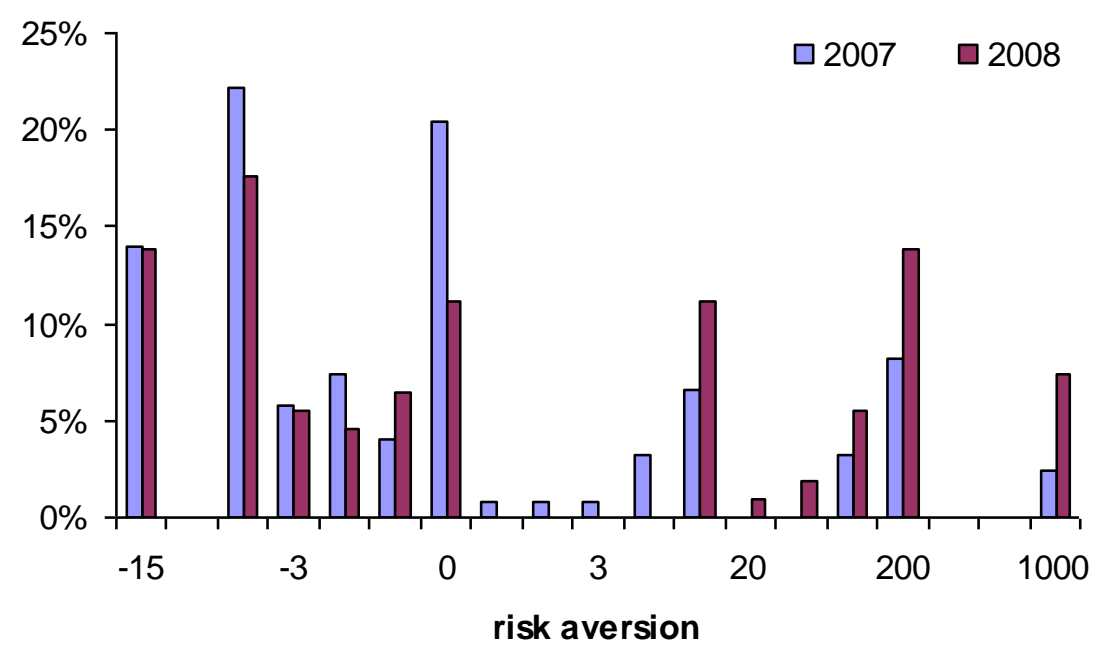


TABLE 7 Risk parameter inference example: worst choices

\begin{tabular}{|c|c|c|c|c|c|c|c|c|c|c|c|c|c|c|c|}
\hline \multirow{2}{*}{\multicolumn{2}{|c|}{$\begin{array}{c}\text { Investment } \\
\text { options }\end{array}$}} & \multirow{2}{*}{\multicolumn{2}{|c|}{$\begin{array}{c}6 \\
\text { RSA }\end{array}$}} & \multirow{2}{*}{\multicolumn{2}{|c|}{$\begin{array}{c}1 \\
\text { cash }\end{array}$}} & \multirow{2}{*}{\multicolumn{2}{|c|}{$\begin{array}{c}2 \\
75: 25\end{array}$}} & \multirow{2}{*}{\multicolumn{2}{|c|}{$\begin{array}{c}3 \\
50: 50\end{array}$}} & \multirow{2}{*}{\multicolumn{2}{|c|}{$\begin{array}{c}4 \\
25: 75\end{array}$}} & \multirow{2}{*}{\multicolumn{2}{|c|}{$\begin{array}{c}5 \\
\text { shares }\end{array}$}} & \multicolumn{2}{|c|}{ selected } \\
\hline & & & & & & & & & & & & & & $\max$ & $\min$ \\
\hline set & best & + & - & + & - & + & - & + & - & + & - & + & - & + & - \\
\hline 17 & 6 & -30 & 4 & & & & & & & & & 5 & 746 & -30 & 4 \\
\hline 18 & 6 & -30 & 11 & & & & & & & 12 & 746 & & & -30 & 11 \\
\hline 19 & 6 & -30 & 7 & & & & & & & & & 8 & 746 & -30 & 7 \\
\hline 20 & 6 & -30 & 10 & & & & & & & & & 11 & 746 & -30 & 10 \\
\hline 21 & 6 & -30 & 7 & & & & & & & & & 8 & 746 & -30 & 7 \\
\hline 22 & 6 & -30 & 7 & & & & & & & 8 & 746 & & & -30 & 7 \\
\hline 23 & 6 & -30 & 4 & & & & & & & & & 5 & 746 & -30 & 4 \\
\hline 24 & 6 & -30 & 15 & & & & & 16 & 18 & 19 & 746 & & & -30 & 15 \\
\hline 25 & 6 & -30 & 11 & & & & & & & & & 12 & 746 & -30 & 11 \\
\hline 26 & 6 & -30 & 7 & & & & & & & & & 8 & 746 & -30 & 7 \\
\hline 27 & 6 & -30 & 7 & & & & & & & 8 & 746 & & & -30 & 7 \\
\hline 28 & 6 & -30 & 4 & & & & & & & & & 5 & 746 & -30 & 4 \\
\hline 29 & 6 & -30 & 20 & & & & & 21 & 325 & & & 326 & 746 & -30 & 20 \\
\hline 30 & 6 & -30 & 4 & & & & & & & & & 5 & 746 & -30 & 4 \\
\hline 31 & 6 & -30 & 10 & & & & & & & & & 11 & 746 & -30 & 10 \\
\hline 32 & 6 & -30 & 7 & & & & & & & & & 8 & 746 & -30 & 7 \\
\hline \multicolumn{14}{|c|}{ Inferred range for risk parameter: } & -30 & 4 \\
\hline \multicolumn{16}{|c|}{$\begin{array}{l}\text { Note: Table gives an example of the } 16 \text { choice sets and 'worst' or least preferred choices of one respondent in the } \\
2008 \text { survey and values of } 2 \eta \text { for which investment options } 1-6 \text { will generate minimum utility } V_{i j} \text { if the respondent }\end{array}$} \\
\hline \multicolumn{16}{|c|}{ behaves consistently with a mean-variance utility function. Each choice made by the respondent implies the range } \\
\hline \multicolumn{16}{|c|}{ for $2 \eta$ in the min-max columns, and the smallest intersection between these ranges is set out in bold in the lower } \\
\hline \multicolumn{16}{|c|}{ right hand cells of the table. We infer that this respondent behaves consistently with absolute risk 'aversion' between } \\
\hline
\end{tabular}


TABLE 8 Summary statistics and histogram: risk preferences for least preferred choices

\begin{tabular}{ccccccc}
\hline & & $\mathbf{2 0 0 7}$ & & & $\mathbf{2 0 0 8}$ & \\
& lower & upper & midpoint & lower & upper & midpoint \\
\hline mean & -10 & 155 & 72 & 5 & 205 & 105 \\
median & -30 & 4 & -13 & -30 & 4 & -13 \\
maximum & 326 & 746 & 536 & 326 & 746 & 536 \\
minimum & -30 & 4 & -13 & -30 & 4 & -13 \\
std. dev & 62 & 296 & 168 & 88 & 328 & 194 \\
observations & 538 & 538 & 538 & 607 & 607 & 607 \\
\hline
\end{tabular}

Note: Table shows summary statistics for cross-section of inferred risk parameters using consistent 'worst' choices from 2007 and 2008 surveys. We report the upper and lower bounds and midpoints of the interval $\left(2 \eta_{i j}{ }^{+} 2 \eta_{i j}{ }^{*}{ }^{*}\right.$ whenever the risk parameter ranges imply a consistent intersection.

\section{Distributions of midpoints of risk parameter intervals}

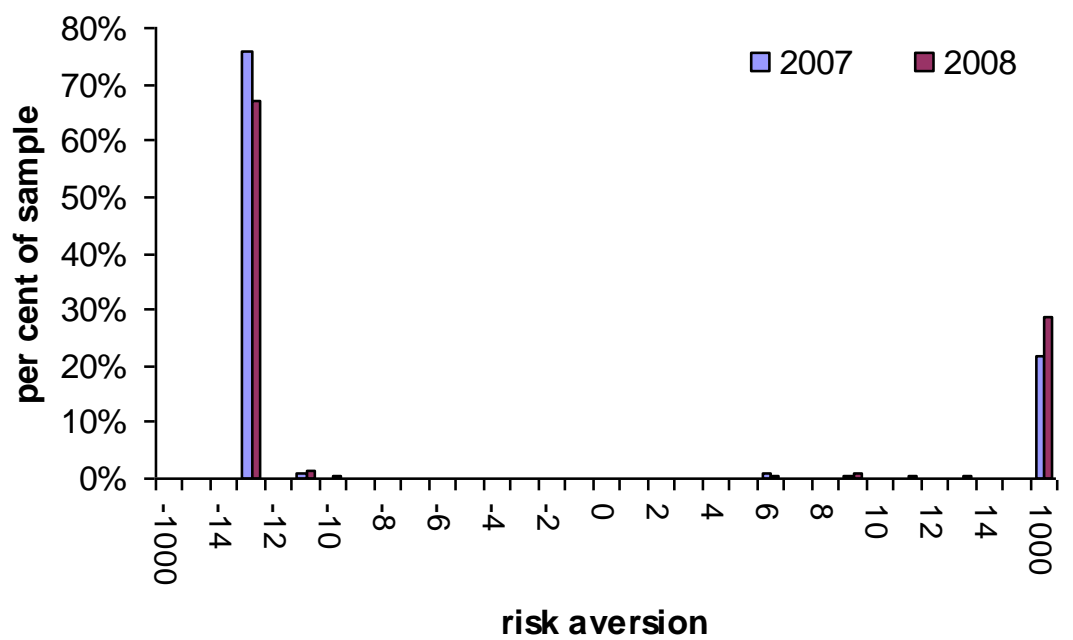


TABLE 9 Multinomial logit estimation of scale factor groups $(D=2)$

\begin{tabular}{lcccc}
\hline & \multicolumn{2}{c}{2007} & \multicolumn{2}{c}{$\mathbf{2 0 0 8}$} \\
\hline & Class $1, \lambda=1$ & Class $2, \lambda=3.37$ & Class $1, \lambda=1$ & Class $2, \lambda=4.00$ \\
\hline & coefficient & coefficient & coefficient & coefficient \\
\hline Intercept & $0.663^{*}$ & $-0.663^{*}$ & 0.279 & -0.279 \\
age: under 24 & $0.144^{*}$ & $-0.144^{*}$ & $0.249^{*}$ & $-0.249^{*}$ \\
age: $25-44$ & -0.007 & 0.007 & -0.081 & 0.081 \\
age: $45-65$ & $-0.137^{*}$ & $0.137^{*}$ & $-0.169^{*}$ & $0.169^{*}$ \\
Risk Score $(/ 100)$ & $-1.657^{*}$ & $1.657^{*}$ & -0.189 & 0.189 \\
\hline \% of sample & 54 & 46 & 57 & 43 \\
\hline
\end{tabular}

Note: Estimation results of the probability that an individual is a member of each scale class where higher values of $\lambda$ indicate less variability. ${ }^{*} p<0.1$. 
TABLE 10 Multinomial logit estimation of preference classes $(Q=7)$

\begin{tabular}{lccccccc}
\hline & Class 1 & Class 2 & Class 3 & Class 4 & Class 5 & Class 6 & Class 7 \\
\hline 2007 & & & & & & & \\
\% of sample (posterior) & 2 & 17 & 15 & 20 & 34 & 2 & 9 \\
\hline Intercept & $-1.188^{*}$ & $0.727^{*}$ & $0.272^{*}$ & $0.350^{*}$ & $1.141^{*}$ & $-1.345^{*}$ & 0.043 \\
age: under 24 & 0.160 & $0.278^{*}$ & $-0.69^{*}$ & $-0.357^{*}$ & -0.221 & 0.108 & $0.662^{*}$ \\
age: 25-44 & 0.137 & $-0.326^{*}$ & $0.301^{*}$ & -0.011 & 0.025 & -0.025 & -0.102 \\
age: 45-65 & -0.297 & 0.048 & $0.328^{*}$ & $0.368^{*}$ & 0.196 & -0.083 & $-0.560^{*}$ \\
income $\leq 40 \mathrm{k}$ & $0.614^{*}$ & -0.210 & -0.257 & -0.119 & $-0.275^{*}$ & 0.467 & -0.220 \\
income>40k & -0.066 & -0.043 & -0.068 & $0.496^{*}$ & $0.205^{*}$ & $-0.553^{*}$ & 0.029 \\
Income unreported & -0.548 & 0.254 & $0.326^{*}$ & $-0.378^{*}$ & 0.070 & 0.086 & 0.191 \\
\hline 2008 & & & & & & & \\
\% of sample (posterior) & 7 & 14 & 17 & 17 & 29 & 3 & 13 \\
\hline Intercept & $-0.575^{*}$ & $0.399^{*}$ & $0.362^{*}$ & 0.135 & $0.673^{*}$ & $-1.099^{*}$ & 0.105 \\
age: under 24 & -0.390 & $0.431^{*}$ & -0.142 & -0.172 & -0.176 & -0.041 & $0.489^{*}$ \\
age: 25-44 & 0.125 & -0.148 & -0.012 & -0.164 & $0.175^{*}$ & -0.115 & 0.140 \\
age: 45-65 & 0.265 & $-0.283^{*}$ & 0.154 & $0.336^{*}$ & 0.001 & 0.156 & $-0.630^{*}$ \\
income $\leq 40 \mathrm{k}$ & 0.065 & $0.314^{*}$ & 0.051 & $-0.403^{*}$ & $-0.319^{*}$ & 0.323 & -0.031 \\
income>40k & -0.106 & -0.089 & 0.050 & $0.391^{*}$ & $0.356^{*}$ & $-0.796^{*}$ & 0.194 \\
Income unreported & 0.041 & -0.226 & -0.101 & 0.012 & -0.037 & $0.474^{*}$ & -0.162 \\
\hline
\end{tabular}

Note: Estimation results of the probability that an individual is a member of each preference class. ${ }^{*} p<0.1$. 
TABLE 11 Conditional logit estimation of choice parameters by preference

class

2007

\begin{tabular}{|c|c|c|c|c|c|c|c|}
\hline \multicolumn{8}{|c|}{ Estimated coefficient } \\
\hline & Class 1 & Class 2 & Class 3 & Class 4 & Class 5 & Class 6 & Class 7 \\
\hline \multicolumn{8}{|l|}{ net return } \\
\hline $100 \%$ cash & $-2.664 *$ & $0.772 *$ & 0.901 & -0.334 & $-5.742 *$ & $-2.683^{*}$ & $4.057 *$ \\
\hline $75: 25 \mathrm{c} / \mathrm{s}$ & -1.409 & $0.547 *$ & $2.401 *$ & $-2.83^{*}$ & -2.833 & -1.288 & 0.782 \\
\hline $50: 50 \mathrm{c} / \mathrm{s}$ & 1.307 & $0.481 *$ & $0.485^{*}$ & $0.545^{*}$ & $1.969 *$ & $2.448 *$ & $0.434 *$ \\
\hline $25: 75 \mathrm{c} / \mathrm{s}$ & -5.599 & -0.819 & -0.884 & 0.075 & $2.439 *$ & -1.583 & $1.536^{*}$ \\
\hline $100 \%$ shares & -1.056 & 0.884 & $3.248 *$ & 0.112 & 0.082 & -0.115 & 0.277 \\
\hline \multicolumn{8}{|l|}{ variance } \\
\hline $100 \%$ cash & 1.725 & -2.600 & 16.995 & 15.000 & 60.723 & 30.714 & -35.417 \\
\hline $75: 25 \mathrm{c} / \mathrm{s}$ & -0.658 & $-0.587 *$ & $2.000 *$ & $5.024^{*}$ & -4.066 & -3.402 & 0.136 \\
\hline $50: 50 \mathrm{c} / \mathrm{s}$ & 0.365 & -0.110 & 0.115 & $1.299 *$ & $1.688^{*}$ & -0.873 & $-1.430 *$ \\
\hline $25: 75 \mathrm{c} / \mathrm{s}$ & 7.619 & $-0.333^{*}$ & -0.116 & $0.340^{*}$ & $1.446^{*}$ & 0.151 & $-1.047 *$ \\
\hline $100 \%$ shares & 1.287 & -0.130 & -0.076 & $0.342 *$ & $0.414 *$ & -0.066 & $-0.769 *$ \\
\hline \multicolumn{8}{|l|}{ constant } \\
\hline $100 \%$ cash & $3.272 *$ & $0.208 *$ & $-1.493 *$ & $-1.771 *$ & $-2.289 *$ & $-0.419 *$ & $-1.914 *$ \\
\hline $75: 25 \mathrm{c} / \mathrm{s}$ & $1.641 *$ & $0.965^{*}$ & $1.066^{*}$ & -0.322 & $-1.589 *$ & -0.202 & $0.558 *$ \\
\hline $50: 50 \mathrm{c} / \mathrm{s}$ & 0.711 & $0.555^{*}$ & $2.493^{*}$ & $1.365^{*}$ & $0.535^{*}$ & -0.144 & $1.144 *$ \\
\hline $25: 75 \mathrm{c} / \mathrm{s}$ & -3.619 & -0.037 & $1.571^{*}$ & $2.386^{*}$ & $2.209^{*}$ & -0.242 & $1.532 *$ \\
\hline $100 \%$ shares & -1.326 & $-0.524 *$ & 0.191 & $1.425^{*}$ & $3.059 *$ & 0.039 & $1.634 *$ \\
\hline
\end{tabular}

Note: $* p<0.1$. 
TABLE 11 (cont) Conditional logit estimation of choice parameters by preference class

\section{8}

\begin{tabular}{|c|c|c|c|c|c|c|c|}
\hline & \multicolumn{7}{|c|}{ Estimated coefficient } \\
\hline & Class 1 & Class 2 & Class 3 & Class 4 & Class 5 & Class 6 & Class 7 \\
\hline \multicolumn{8}{|l|}{ net return } \\
\hline $100 \%$ cash & -0.585 & $0.637^{*}$ & 1.376 & -1.724 & -2.378 & $-1.955^{*}$ & -1.782 \\
\hline $75: 25 \mathrm{c} / \mathrm{s}$ & -1.264 & 0.219 & 0.627 & 1.220 & 2.181 & -1.136 & -0.179 \\
\hline $50: 50 \mathrm{c} / \mathrm{s}$ & -1.303 & $0.288^{*}$ & $1.136^{*}$ & $0.315^{*}$ & $1.940 *$ & 0.360 & $0.315^{*}$ \\
\hline $25: 75 \mathrm{c} / \mathrm{s}$ & 0.441 & 0.957 & 1.252 & 0.0 .583 & $1.907 *$ & 2.224 & -0.324 \\
\hline $100 \%$ shares & -1.320 & -0.290 & $3.325^{*}$ & -0.059 & $0.531 *$ & $-5.225^{*}$ & $0.555^{*}$ \\
\hline \multicolumn{8}{|l|}{ variance } \\
\hline $100 \%$ cash & 0.899 & 4.225 & $-136.973^{*}$ & -58.053 & 24.915 & $73.822 *$ & 43.443 \\
\hline $75: 25 \mathrm{c} / \mathrm{s}$ & $-2.756^{*}$ & $-0.527^{*}$ & 0.647 & 3.107 & $4.793^{*}$ & -1.081 & 0.004 \\
\hline $50: 50 \mathrm{c} / \mathrm{s}$ & 1.278 & $-0.379 *$ & -0.210 & $0.755^{*}$ & $2.163 *$ & -0.578 & $-0.541 *$ \\
\hline $25: 75 \mathrm{c} / \mathrm{s}$ & $-1.027 *$ & -0.076 & -0.121 & $0.284 *$ & $1.209 *$ & -0.123 & $-0.460 *$ \\
\hline $100 \%$ shares & -0.312 & 0.085 & -0.309 & $0.791 *$ & $0.368^{*}$ & 0.149 & $-0.392 *$ \\
\hline \multicolumn{8}{|l|}{ constant } \\
\hline $100 \%$ cash & $2.014^{*}$ & $0.191 *$ & $-2.037 *$ & -1.428 & $-1.747 *$ & -0.242 & $-1.011 *$ \\
\hline $75: 25 \mathrm{c} / \mathrm{s}$ & $0.840 *$ & $0.949 *$ & $1.267 *$ & 0.509 & $-1.024 *$ & -0.186 & $0.353 *$ \\
\hline $50: 50 \mathrm{c} / \mathrm{s}$ & $-0.383^{*}$ & $0.386^{*}$ & $2.406^{*}$ & $2.704 *$ & $0.361 *$ & 0.075 & $0.765^{*}$ \\
\hline $25: 75 \mathrm{c} / \mathrm{s}$ & $-0.484^{*}$ & $-0.150 *$ & $1.110^{*}$ & $3.468^{*}$ & $1.795^{*}$ & $-0.364^{*}$ & $0.958 *$ \\
\hline $100 \%$ shares & $-0.599 *$ & $-0.437 *$ & $-0.576^{*}$ & 1.585 & $2.490^{*}$ & $-0.694 *$ & $0.864^{*}$ \\
\hline
\end{tabular}

Note: $* p<0.1$ 
TABLE 12 Marginal change in choice probabilities by preference class

\begin{tabular}{|c|c|c|c|c|c|c|c|}
\hline \multirow{2}{*}{$\begin{array}{l}2007 \\
\text { Attribute } \\
\end{array}$} & \multicolumn{7}{|c|}{ Significant marginal effect, $\lambda=1$} \\
\hline & Class 1 & Class 2 & Class 3 & Class 4 & Class 5 & Class 6 & Class 7 \\
\hline \\
\hline $100 \%$ cash & -0.52 & 0.11 & & & -0.03 & -0.25 & 0.05 \\
\hline $75: 25 \mathrm{c} / \mathrm{s}$ & & 0.12 & 0.29 & -0.11 & & & \\
\hline $50: 50 \mathrm{c} / \mathrm{s}$ & & 0.09 & 0.12 & 0.09 & 0.11 & 0.28 & 0.07 \\
\hline $25: 75 \mathrm{c} / \mathrm{s}$ & & & & & 0.51 & & 0.33 \\
\hline $100 \%$ shares & & & 0.19 & 0.00 & & & \\
\hline \multicolumn{8}{|l|}{ variance } \\
\hline \multicolumn{8}{|l|}{$100 \%$ cash } \\
\hline $75: 25 \mathrm{c} / \mathrm{s}$ & & -0.08 & 0.15 & 0.12 & & & \\
\hline $50: 50 \mathrm{c} / \mathrm{s}$ & & & & 0.18 & 0.08 & & -0.21 \\
\hline $25: 75 \mathrm{c} / \mathrm{s}$ & & -0.05 & & 0.10 & 0.36 & & -0.27 \\
\hline $100 \%$ shares & & & & 0.09 & 0.15 & & -0.27 \\
\hline \multicolumn{8}{|l|}{2008} \\
\hline \multicolumn{8}{|l|}{ net return } \\
\hline $100 \%$ cash & & 0.09 & & & & -0.20 & \\
\hline \multicolumn{8}{|l|}{$75: 25 \mathrm{c} / \mathrm{s}$} \\
\hline $50: 50 \mathrm{c} / \mathrm{s}$ & & 0.05 & 0.27 & 0.06 & 0.14 & & 0.06 \\
\hline $25: 75 \mathrm{c} / \mathrm{s}$ & & & & & 0.41 & & \\
\hline $100 \%$ shares & & & 0.11 & & 0.13 & -0.38 & 0.11 \\
\hline \multicolumn{8}{|l|}{ variance } \\
\hline $100 \%$ cash & & & -0.69 & & & 2.81 & \\
\hline $75: 25 \mathrm{c} / \mathrm{s}$ & -0.26 & -0.07 & & & 0.05 & & \\
\hline $50: 50 \mathrm{c} / \mathrm{s}$ & & -0.05 & & 0.13 & 0.14 & & -0.08 \\
\hline $25: 75 \mathrm{c} / \mathrm{s}$ & -0.06 & & & 0.08 & 0.31 & & -0.11 \\
\hline $100 \%$ shares & & & & 0.12 & 0.14 & & -0.12 \\
\hline
\end{tabular}

Note: Table shows the change average probability $P(j \mid q, d)$ of choice of investment option $j$ for each preference class, where scale $\lambda=1$, given a 100 basis point ( 1 percentage point) increase in net return $j$ or a 500 basis point ( 5 percentage point) increase in annual portfolio volatility for portfolio $j$. Estimated effects with $p$-values of 0.1 or less are reported and effects for the most preferred investment option for each class are in bold typeface. 
TABLE 13 Marginal change in choice probabilities, cross-effects by preference class

\begin{tabular}{|c|c|c|c|c|c|c|c|}
\hline \multirow{2}{*}{$\begin{array}{l}2007 \\
\text { Attribute }\end{array}$} & \multicolumn{7}{|c|}{ Significant marginal effect $\lambda=1$} \\
\hline & Class 1 & Class 2 & Class 3 & Class 4 & Class 5 & Class 6 & Class 7 \\
\hline \multicolumn{8}{|l|}{ net return } \\
\hline $100 \%$ cash & $* *$ & -0.05 & & & & 0.09 & \\
\hline $75: 25 \mathrm{c} / \mathrm{s}$ & & $* *$ & -0.23 & 0.08 & 0.02 & & \\
\hline $50: 50 \mathrm{c} / \mathrm{s}$ & & -0.03 & $* *$ & -0.06 & -0.02 & -0.11 & -0.05 \\
\hline $25: 75 \mathrm{c} / \mathrm{s}$ & & & & $* *$ & & & -0.04 \\
\hline $100 \%$ shares & & -0.04 & -0.07 & & $* *$ & & $* *$ \\
\hline RSA & & & & & & $* *$ & \\
\hline \multicolumn{8}{|l|}{ variance } \\
\hline $100 \%$ cash & $* *$ & & & & & & \\
\hline $75: 25 \mathrm{c} / \mathrm{s}$ & & $* *$ & -0.09 & -0.07 & & & \\
\hline $50: 50 \mathrm{c} / \mathrm{s}$ & & & $* *$ & -0.12 & -0.05 & & 0.09 \\
\hline $25: 75 \mathrm{c} / \mathrm{s}$ & & 0.01 & & $* *$ & -0.32 & & 0.14 \\
\hline $100 \%$ shares & & & & -0.06 & $* *$ & & $* *$ \\
\hline RSA & & & & & & $* *$ & \\
\hline \multicolumn{8}{|l|}{2008} \\
\hline \multicolumn{8}{|l|}{ net return } \\
\hline $100 \%$ cash & $* *$ & -0.04 & & & & 0.11 & \\
\hline $75: 25 \mathrm{c} / \mathrm{s}$ & & $* *$ & & & & & \\
\hline $50: 50 \mathrm{c} / \mathrm{s}$ & & -0.02 & $* *$ & -0.05 & -0.09 & & 0.01 \\
\hline $25: 75 \mathrm{c} / \mathrm{s}$ & & & & $* *$ & -0.34 & & $* *$ \\
\hline $100 \%$ shares & & & -0.07 & & $* *$ & -0.09 & 0.03 \\
\hline \multicolumn{8}{|l|}{ variance } \\
\hline $100 \%$ cash & $* *$ & & -0.03 & & & -1.56 & \\
\hline $75: 25 \mathrm{c} / \mathrm{s}$ & 0.20 & $* *$ & & & -0.06 & & \\
\hline $50: 50 \mathrm{c} / \mathrm{s}$ & & & $* *$ & -0.11 & -0.19 & & 0.03 \\
\hline $25: 75 \mathrm{c} / \mathrm{s}$ & 0.04 & & & $* *$ & -0.26 & & $* *$ \\
\hline $100 \%$ shares & & & & -0.08 & $* *$ & & 0.05 \\
\hline
\end{tabular}

Note: Table shows marginal change in probability of choosing the most preferred investment $(j)$ for each scale class,

$P(j \mid q, d)$, for a 100 basis point (1 percentage point) increase in annual net return to investment option $i$ or a 500 basis point ( 5 percentage point) increase portfolio volatility (annual standard deviation) for option $i$. The most probable choice for each preference class is indicated by two asterisks. Results for scale class $\lambda=1$ and estimated cross effects with $p$-values of 0.1 or less are reported. 


\section{RETIREMENT INVESTOR RISK TOLERANCE IN CRISIS AND CALM}

${ }^{1}$ Bateman et al. (2009) gives an econometric analysis of a sub-sample of results for the 2007 survey. Here we include a full sample of respondents for both the 2007 and 2008 surveys, including individuals who did not provide household income data and other new results on risk parameters.

${ }^{2}$ Like many risk profiling questionnaires, this questionnaire used by one of Australia's largest financial service providers, AMP, was not tested or calibrated (see Yook and Everett 2003), but published in consumer information for investment products and in generally use by industry practitioners. As a result we report the results of the risk profiling questionnaire with caution. We did not inform respondents of their scores during the survey.

${ }^{3}$ Average household earnings in 2007-08 were around \$80,000 AUD.

${ }^{4}$ While the $\$ 1000$ may seem trivial in isolation, the survey introduction prompts the respondents to think about the contribution in conjunction with their (existing) superannuation (pension) fund and retirement accumulation, rather than as a one-off amount. The $\$ 1000$ contribution is hypothetical and clearly a small amount for many retirement savers, however, the literature does suggest a close relationship between revealed and stated preferences (surveyed in Louviere, Hensher and Swait 2000, Chapter 13

${ }^{5}$ A retirement savings account is a product offered by an Australian financial services provider as an alternative to a superannuation (pension) fund. It pays a fixed, net of fees, interest rate, which is generally lower than one would expect from investing in a 'cash' option from a pension fund investment option menu.

${ }^{6}$ The major types of fees on superannuation accumulation accounts could include: 1$)$ Contribution fees (4-4.5\% of all contributions), charged to open the account and on all later contributions. 2) Management or investment fees, linked to chosen investments and varying from manager to manager. They may include additional performance fees, and/or rebates on larger. 3) Administration or member fees, charged as a percentage of the account balance or as a fixed fee but sometimes bundled with investment management fees. 4) Switching investment options or other transactions by members, sometimes including a fee on the termination of the account. 5) Ongoing payments to advisers as part of the investment agreement.

${ }^{7}$ Return and risk attributes for each option are bootstrapped from a sample of monthly time series running from July 1986 to March 2006 of the JP Morgan Australian Cash 12 months total return index (DataStream JPAU12L A\$), 
end-month and the Australia-DS Market total return index (DataStream TOTMKAU(RI)), end-month. We deflated using the ABS Private Consumption Deflator, quarterly, linearly interpolated to monthly frequency. Bootstrapped monthly returns are accumulated to 10 year gross returns.

${ }^{8}$ Note that the last four variables also change with attribute level, but we do not index again so as to keep the notation simple.

${ }^{9}$ More specifically portfolio option $j=6$.

${ }^{10}$ In 2008 , one respondent selected from 11 rather than 16 choice sets producing a total of 14699 rather than 14704 responses.

${ }^{11}$ We report only the best models below but preliminary model estimations are available from the authors on request.

${ }^{12}$ Hallahan, Faff and McKenzie (2003) show that similar psychometric risk profiling scores can themselves be related to demographic characteristics including income, age and gender. Preliminary ordinal regression of risk scores on demographics by respondent showed that very low and very high income significantly predicted the risk score (low incomes associated with low scores and vice versa) and similarly for education where a university degree predicted high scores and a secondary education or less predicted low scores. We do not report these results here but they are available from the authors on request.

xiii In some respects this description follows Greene and Hensher (2003). 